\title{
LA-UR-97- -5011
}

Title:

THE EFFECTS OF 800 MeV PROTON IRRADIATION ON THE CORROSION OF TUNGSTEN, TANTALUM, STAINLESS STEEL, AND GOLD

Author(s):

R. SCOTT LILLARD, MST-6

DARRYL P. BUTT, MST-6

Submitted to:

END OF FISCAL YEAR REPORT FOR

INTERNAL/EXTERNAL DISSEMINATION

DISTRIBUTION OF THIS DOCUMENT IS UNLMITED 


\section{DISCLAIMER}

This report was prepared as an account of work sponsored by an agency of the United States Government. Neither the United States Government nor any agency thereof, nor any of their empioyees, makes any warranty, express or implied, or assumes any legal liability or responsibility for the accuracy, completeness, or usefulness of any information, apparatus, product, or process disclosed, or represents that its use would not infringe privately owned rights. Reference herein to any specific commercial product, process, or service by trade name, trademark, manufacturer, or otherwise does not necessarily constitute or imply its endorsement, recommendation, or favoring by the United States Government or any agency thereof. The views and opinions of authors expressed herein do not necessarily state or reflect those of the United States Government or any agency thereof. 


\title{
Materials Corrosion and Mitigation Strategies for APT, Weapons Neutron Research Facility Experiments:
}

The Effects of $800 \mathrm{MeV}$ Proton Irradiation on the Corrosion of Tungsten, Tantalum, Stainless Steel, and Gold

\author{
R. Scott Lillard, Darryl P. Butt \\ Materials Corrosion \& Environmental Effects Laboratory \\ MST-6, Metallurgy \\ Gary Kanner \\ MST-6, Metallurgy \\ Luke Daemen \\ LANSCE-LER \\ RECEIVI \\ APR 0619 \\ OST \\ Los Alamos National Laboratory \\ Los Alamos, New Mexico 87545 \\ submitted to: \\ RECEIVED \\ APR 061998 \\ OSTI
}

\section{Laurie Waters}

APT Project Office

December 1, 1997

contributors:

Donald Pile, MST-6

Gordon Willcutt, TSA-10

Phil Ferguson, LANSCE-LER

John Ullmann, LANSCE-3 


\section{Executive Summary}

Summary of Results Real time electrochemical data were acquired for tungsten, tantalum, stainless steel 304L, and gold targets during proton irradiation at the LANSCE Weapons Neutron Research Facility. The goal of this research was to establish a better understanding of the corrosion properties of materials as a function of proton irradiation and gain insight into the mechanism of the observed phenomena.

The following electrochemical observations were made during proton irradiation of $\mathrm{W}, \mathrm{Ta}$, SS304, and Au:

1) The open circuit potential of all materials increased with increasing proton fluence

2) The corrosion rate (at the OCP) of W and SS304 increased with increasing proton fluence

3) The passive dissolution rate for SS304 and Ta decreased with increasing proton fluence

4) The anodic dissolution rate for $W$ increased with increasing proton fluence

5) The pitting potential for SS304 increased with proton fluence, which is an indication that the material is less susceptible to pitting attack during irradiation.

While no "global" theory of proton beam effects on the electrochemical properties of materials has been established, additional measurements were conducted during the Wgrg experiments to examine possible mechanisms. To measure the effects of proton irradiation on the passive oxide, Surface Enhanced Raman Spectroscopy (SERS) experiments were conducted on WV as a function of proton beam current. SERS, is a powerful technique for examining the properties of the thin (less than $10 \times 10^{-9}$ meters thick) oxide which forms on metals. This includes changes in structure, composition, hydration, and oxidation state. Additional experiments which address water radiolysis were also performed. The results of each of these studies (SERS / radiolysis) are reported in separate but attached documents.

To rule out the effects of energy deposition (from the proton beam) on the surface temperature as a possible mechanism for the observed electrochemical effects during irradiation, energy deposition and thermal hydraulic calculations for the rod-shaped tungsten target were performed. The maximum surface temperatures (for a beam current of $484 \mathrm{nA}$ ) are $4.8^{\circ}$ and $5.1^{\circ}$ $\mathrm{C}$ above the water temperature $\left(30.8^{\circ}\right.$ and $\left.31.1^{\circ} \mathrm{C}\right)$. This is only a $0.2 \%$ change in surface temperature and, as corrosion rate is proportional to temperature in degrees Kelvin, can not account for the observed electrochemical changes.

The following sections in this Executive Summary provide a brief overview of the results in (1-5) above. The body of the text gives the complete details of all of our WNR corrosion experiments.

Effect of Beam current on the Open Circuit Potential The open circuit potential (OCP) for these materials was measured as a function of time and proton fluence. Typically, when the proton beam was turned on a large positive increase in the OCP was observed. This effect is shown for stainless steel 304 in $\mathrm{H}_{2} \mathrm{SO}_{4} \mathrm{pH} 1.6$ at a proton beam current of $100 \mathrm{nA}$ in Figure 1.es below. While a positive shift in the OCP is consistent with the formation of radiolysis products such as hydrogen peroxide, the rapid response of the system from beam off to beam on abruptly followed by a plateau in the OCP is not consistent with a steadily increasing concentration of radiolysis products. Moreover, this trend is also consistent with a change in the oxide surface state. 


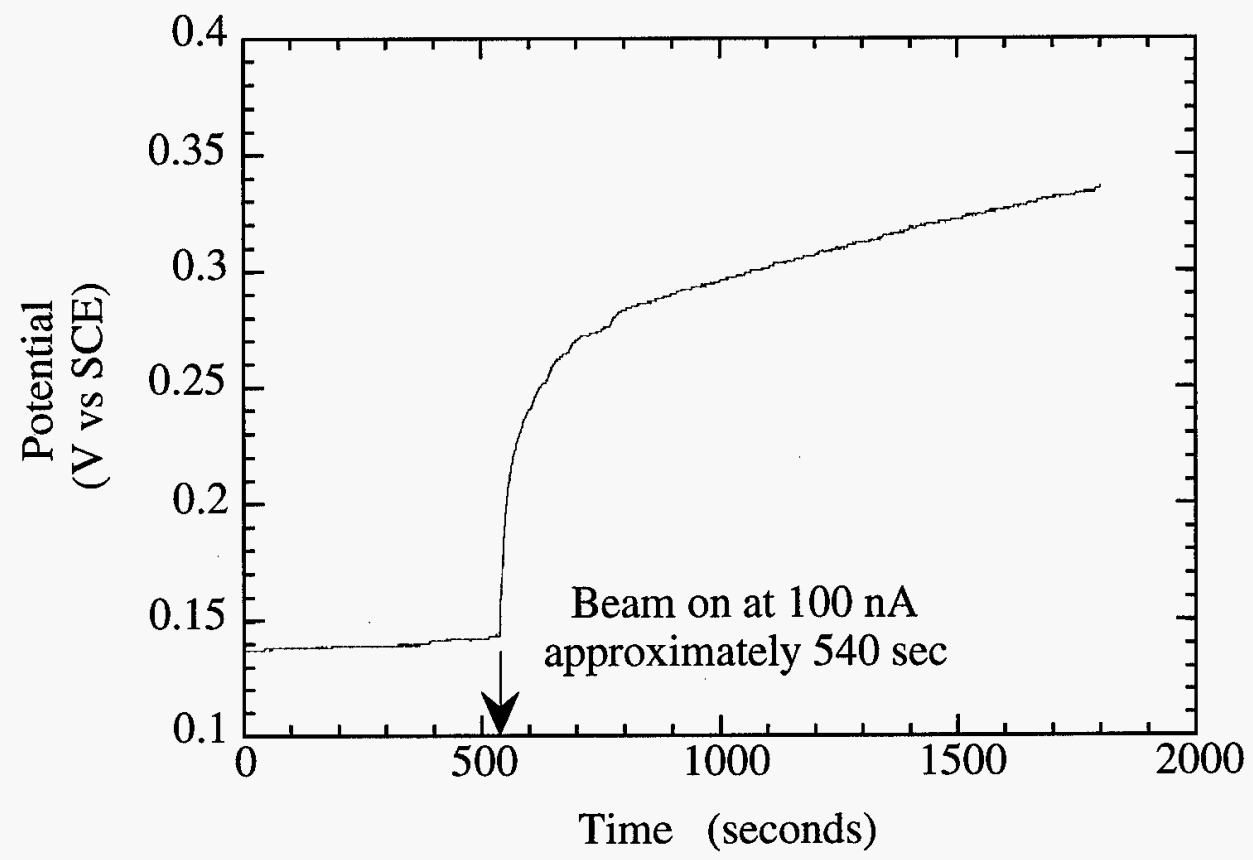

Figure 1.es Open circuit potential for SS304 in flow cell with $\mathrm{H}_{2} \mathrm{SO}_{4}$. Plot shows pre-beam values and value during irradiation at $100 \mathrm{nA}$.

Effects of Proton Irradiation on $W$ To distinguish between an increase in cathodic reaction kinetics (which will result from hydrogen peroxide production) and radiation "enhanced" anodic reaction kinetics, EIS experiments for $\mathrm{W}$ in $0.10 \mathrm{M} \mathrm{NaCl}(\mathrm{pH} 5.2)$ were performed at an applied anodic potential of $0.0 \mathrm{~V} \mathrm{SCE}$. This potential is near the mass transport limited dissolution rate for W. Typical EIS data before the beam was turned on and for beam currents of $141 \mathrm{nA}$ and $484 \mathrm{nA}$ are presented in Figure 2.es in the form of Nyquist plots. Nyquist plots graph the imaginary impedance as a function of the real component of the impedance. As seen in Figure 2.es, there is a precipitous decrease in the low frequency impedance of the tungsten target as beam current is increased. Recall that a decrease in impedance correlates with an increase in metal dissolution rate.

The enhanced dissolution rates observed during in-beam EIS experiments in $0.1 \mathrm{M} \mathrm{NaCl}$ at applied potentials are complemented by potentiodynamic polarization curves for $\mathrm{W}$ generated during irradiation at a proton beam current of $100 \mathrm{nA}$. In-beam and out-of-beam potentiodynamic polarization curves for $\mathrm{W}$ in $\mathrm{NaCl}(\mathrm{pH} \mathrm{5.2)}$ ) are presented in Figure 3.es. As shown in this figure both the corrosion rate (dissolution rate at the OCP) and the dissolution rate at applied anodic potentials increase in the presence of proton irradiation.

To summarize, the in-beam W results, both EIS and potentiodynamic polarization experiments found that the anodic dissolution rate of $\mathrm{W}$ increased with increasing proton beam current in both $\mathrm{pH} 1.6$ and 5.2 solutions. In addition, potentiodynamic polarization experiments demonstrated that the corrosion rate of $\mathrm{W}$ increased with increasing proton beam current in all solutions examined. 


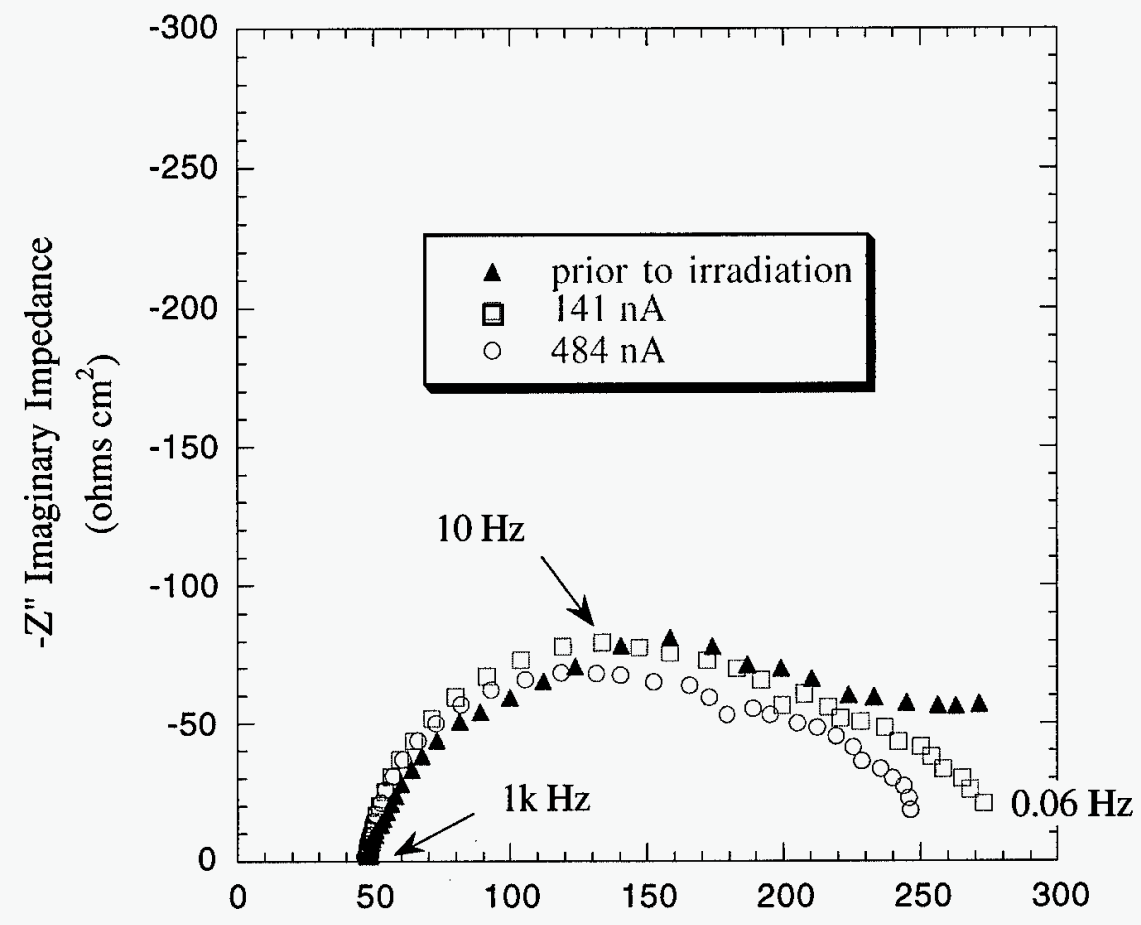

Z' Real Impedance $\left(\mathrm{ohm} \mathrm{cm}^{2}\right.$ )

Figure 2.es Nyquist plots for tungsten in $0.10 \mathrm{M} \mathrm{NaCl}$ as a function of proton beam current.

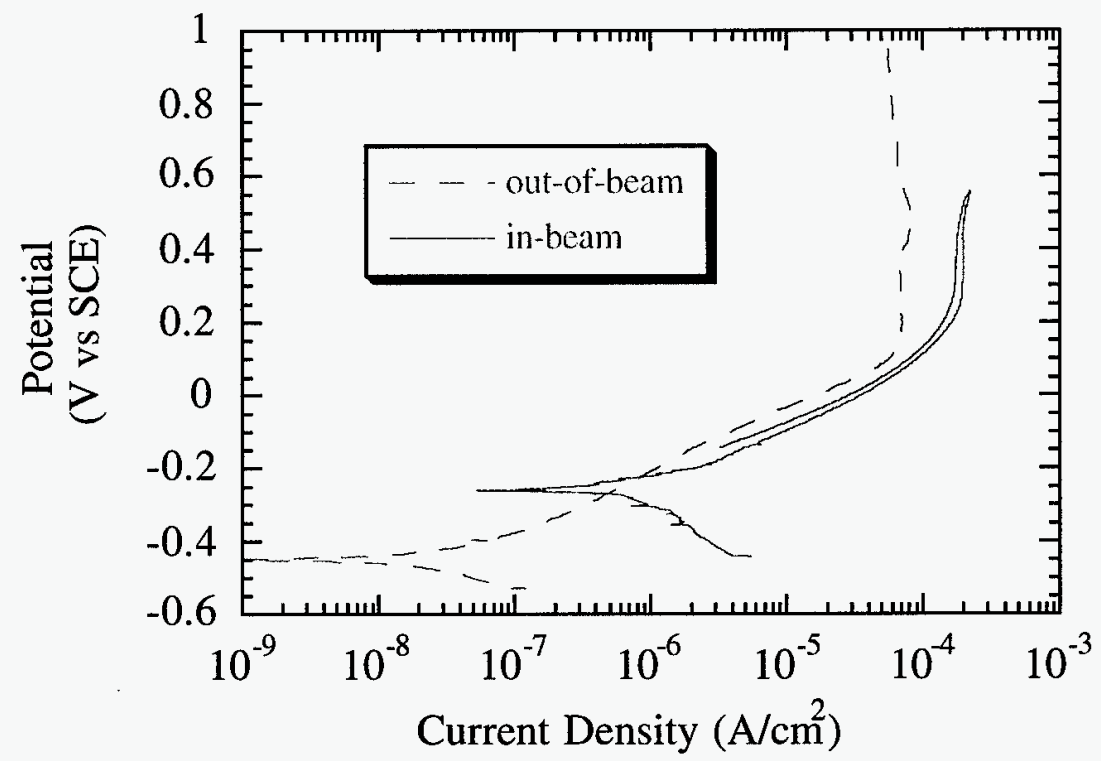

Figure 3.es Potentiodynamic polarization curves for $\mathrm{W}$ in $0.1 \mathrm{M} \mathrm{NaCl} \mathrm{pH} 5.2$ during irradiation at a proton beam current of $100 \mathrm{nA}$ (in-beam) and with no exposure to irradiation (out-of-beam). 
Effects of Proton Irradiation on Stainless Steel 304 In contrast to EIS data for W presented above, the low frequency EIS data for SS304 in sulfuric acid $\left(\mathrm{H}_{2} \mathrm{SO}_{4}\right) \mathrm{pH} 1.6$ increases with increasing proton beam current (data not shown). This result was in agreement with potentiodynamic polarization curves for SS304 in this solution (Figure 5.es). In these experiments, the in-beam specimen is associated with a higher OCP at 100nA although the corrosion current density $\left(i_{\text {cor }}\right.$ ) appears to be similar to that of the out-of-beam sample. In addition, the passive current density $\left(\mathrm{i}_{\text {pass }}\right)$ for the in-beam appears to be somewhat lower than the out-ofbeam sample. Although this difference is small it was reproducible and, in conjunction with the EIS measurements where the charge transfer resistance was found to increase with beam current there is a convincing argument that passive dissolution of SS304 is lowered by interactions with high energy proton irradiation. It is also interesting to note that during the reverse scan a step to lower current densities was observed when the proton beam was shut off. Moreover, this step "returns" the current density to a value identical to that measured for the out-of-beam sample. This is an indication that the electrochemical effects of high energy proton beam interaction with the electrode are reversible.

Additional experiments for SS304 during irradiation were conducted in $0.1 \mathrm{M} \mathrm{NaCl}$. Potentiodynamic polarization curves from these experiments are presented in Figure 4.es for samples during irradiation at a proton beam current of $100 \mathrm{nA}$ (in-beam) and not exposed to irradiation (out-of-beam). As can be seen in this figure, while the passive current densities are comparable for the two samples the corrosion current density is somewhat greater for the in-beam sample. In addition, the pitting potential $\left(\mathrm{E}_{\mathrm{pit}}\right)$ for the in-beam sample is $0.662 \mathrm{~V}$ while the mean value for 3 out-of-beam samples was $0.495 \mathrm{~V}+/-37 \mathrm{mV}$. This is an increase in $E_{\text {pit }}$ of approximately $170 \mathrm{mV}$, a value which is $4.6 \sigma$ over the mean out-of-beam value indicating that the observed increase is statistically significant. While these results are preliminary, it is an indication that SS304 is less susceptible to pitting attack during irradiation. In comparison, Sikora et al

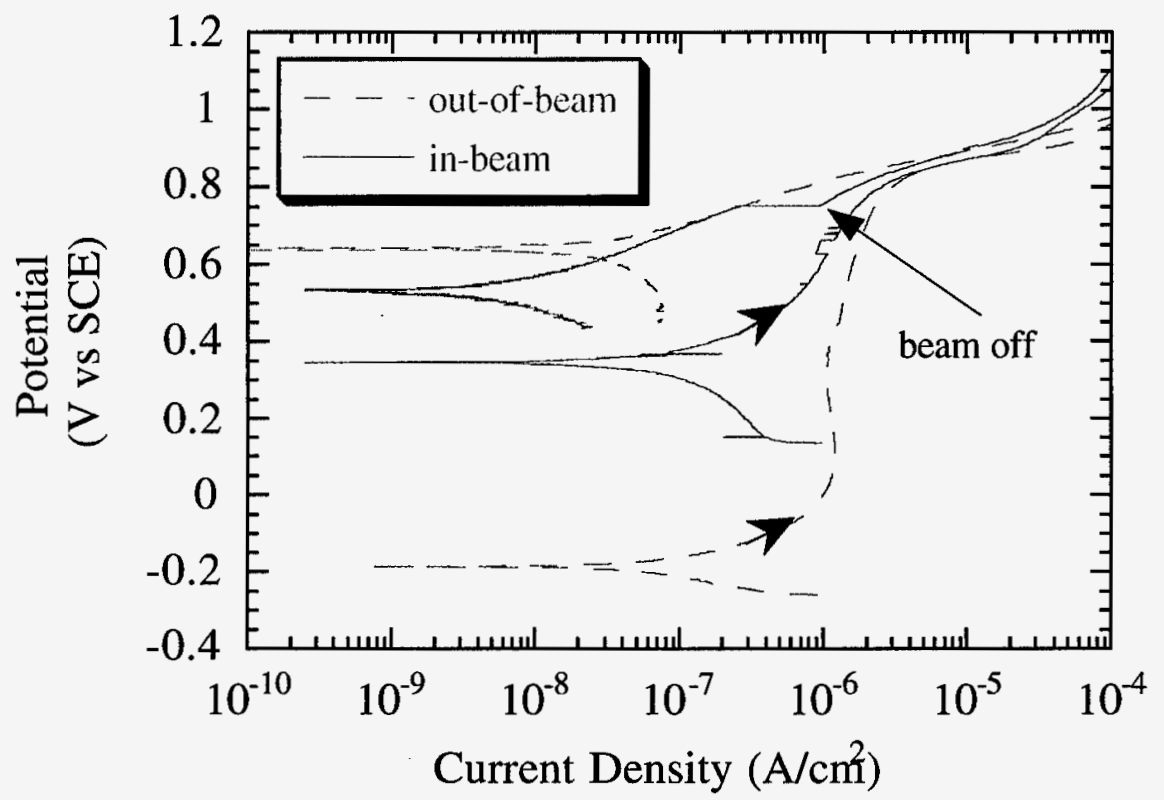

Figure 4.es Potentiodynamic polarization curves for $\mathrm{SS} 304$ in $\mathrm{H}_{2} \mathrm{SO}_{4} \mathrm{pH} 1.6$ for samples during irradiation at a proton beam current of $100 \mathrm{nA}$ (in-beam) and a sample not exposed to irradiation (out-of-beam). 


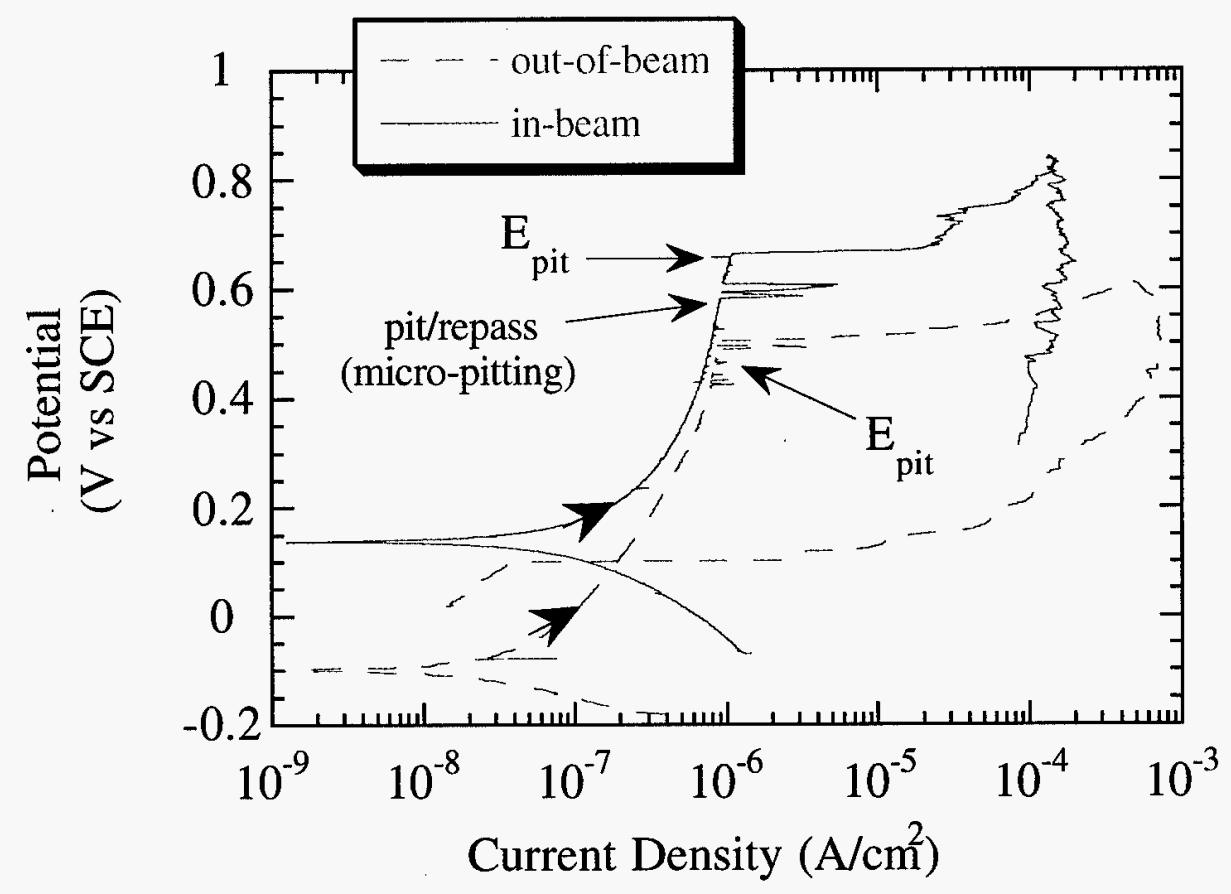

Figure 5.es Potentiodynamic polarization curves for SS304 in $0.1 \mathrm{M} \mathrm{NaCl}$ for a sample during irradiation at a proton beam current of $100 \mathrm{nA}$ (in-beam) and a sample not exposed to irradiation (out-of-beam).

found that the pitting potential for SS304 was increased by $60 \mathrm{mV}$ during photon irradiation as compared to samples not exposed to light. It was determined (via Mott Schottky plots) that the increase in pitting potential owed to a change in the conductivity of the passive oxide on SS304. It is also interesting to note that the OCP of the in-beam sample is approximately $50 \mathrm{mV}$ more positive than the repassivation potential $\left(E_{r p}\right)$ for the out-of-beam sample. This indicates that once a stable pit is formed, it does not repassivate. 
Table of Contents

\section{Page}

Executive Summary

ii

Summary of Results

ii

Effects of Proton Irradiation on $W$

iii

Effects of Proton Irradiation on Stainless Steel 304

v

List of Figures

viii

Introduction

1

Background

1

Experimental

5

Results and Discussion

8

Effect of Beam Current on the Open Circuit Potential

8

Effects of Proton Irradiation on $W$

10

Effects of Proton Irradiation on Stainless Steel 304

16

Effects of Proton Irradiation on Tantalum

19

Effects of Proton Irradiation on Gold

22

Thermal Hydraulic Considerations

26

Summary

27

References 


\section{List of Figures}

Figure Page

Figure 1 Diagram depicting proton beam profile at the Weapons Neutron

Research facility at LANSCE. The spacing between each micropulse is also given with respect to the beam current.

Figure 2 Diagrams depicting a) "half-round" tungsten target and b) electrochemical flow cell used in WNR irradiation experiments. WE denotes working electrode (W target), RE denotes reference electrode (SCE) and, CE denotes counter electrode (platinum mesh).

Figure 3 Open circuit potential for $\mathrm{W}$ in flow cell with $0.1 \mathrm{M} \mathrm{NaCl}$. Plot shows pre-beam values, change in OCP during positioning of beam, and steady state irradiation at $50 \mathrm{nA}$.

Figure 4 Open circuit potential for $\mathrm{W}$ in $0.10 \mathrm{M} \mathrm{NaCl}$ as a function of proton beam current. Plot also shows change in open circuit potential from previous beam current as a function of beam current.

Figure 5 Open circuit potential for $\mathrm{SS} 304$ in flow cell with $\mathrm{H}_{2} \mathrm{SO}_{4}$. Plot shows pre-beam values and value during irradiation at $100 \mathrm{nA}$.

Figure 6 Nyquist plots for the WNR tungsten target in $0.10 \mathrm{M} \mathrm{NaCl}$ as a function of proton beam current.

Figure 7 Electrical equivalent circuit representing the tungsten corrosion system where a) $R_{c t}$ represents the charge transfer resistance (inversely proportional to metal dissolution rate), $\mathrm{C}_{\mathrm{dl}}$ represents the double layer capacitance, $\mathrm{R}_{\text {sol }}$ represents the geometric solution resistance, and $\mathrm{W}$ represents a Warburg type diffusional impedance; in b) $R_{a s}$ represents the resistance of an adsorbed intermediate and $\mathrm{C}_{\mathrm{as}}$ represents an adsorption psuedocapacitance.

Figure 8 Nyquist plot showing the tungsten target in $0.10 \mathrm{M} \mathrm{NaCl}$ during irradiation at $484 \mathrm{nA}$ and the fitted data based on the EC presented in Figure 7. As shown in this figure, the high frequency time constant was attributed to the charge transfer resistance while the low frequency time constant was attributed to an adsorbed intermediate.

Figure 9 Potentiodynamic polarization curves for $\mathrm{W}$ in $0.1 \mathrm{M} \mathrm{NaCl} \mathrm{pH}$ 5.2 for a sample during irradiation at a proton beam current of $100 \mathrm{nA}$ (in-beam) and a sample not exposed to irradiation (out-of-beam).

Figure 10 Nyquist plot for $\mathrm{W}$ in $\mathrm{H}_{2} \mathrm{SO}_{4}, \mathrm{pH} 1.6$ at an applied potential of $+0.225 \mathrm{~V}$ SCE. Plot shows the effect of beam current on passive dissolution rate based on the EC presented in Figure 7. 
Figure 11 Potentiodynamic polarization curves for $\mathrm{W}$ in $\mathrm{H}_{2} \mathrm{SO}_{4}(\mathrm{pH}=1.6)$ for a sample during irradiation at a proton beam current of $100 \mathrm{nA}$ (in-beam) and a sample not exposed to irradiation (out-of-beam).

Figure 12 Nyquist plot for $\mathrm{SS} 304$ in $\mathrm{H}_{2} \mathrm{SO}_{4}, \mathrm{pH} 1.6$ at an applied potential of $+0.580 \mathrm{~V} \mathrm{SCE}$. Plot shows the effect of beam current on passive dissolution rate.

Figure 13 Potentiodynamic polarization curves for $\mathrm{SS} 304$ in $\mathrm{H}_{2} \mathrm{SO}_{4} \mathrm{pH} 1.6$ for a sample during irradiation at a proton beam current of $100 \mathrm{nA}$ (in-beam) and a sample not exposed to irradiation (out-of-beam).

Figure 14 Potentiodynamic polarization curves for SS304 in $0.1 \mathrm{M} \mathrm{NaCl}$ for a sample during irradiation at a proton beam current of $100 \mathrm{nA}$ (in-beam) and a sample not exposed to irradiation (out-of-beam).

Figure 15 Nyquist plot for $\mathrm{Ta}$ in $\mathrm{H}_{2} \mathrm{SO}_{4}, \mathrm{pH} 1.6$ at an applied potential of $+0.580 \mathrm{~V} \mathrm{SCE}$. Plot shows the effect of beam current on passive dissolution rate.

Figure 16 Potentiodynamic polarization curves for Ta in $\mathrm{H}_{2} \mathrm{SO}_{4} \mathrm{pH} 1.6$ for a sample during irradiation at a proton beam current of $100 \mathrm{nA}$ (in-beam) and a sample not exposed to irradiation (out-of-beam).

Figure 17 Potentiodynamic polarization curves for Ta in $0.1 \mathrm{M} \mathrm{NaCl}$ for a sample during irradiation at a proton beam current of $100 \mathrm{nA}$ (in-beam) and a sample not exposed to irradiation (out-of-beam).

Figure 18 Cyclic voltamograms for gold in $\mathrm{H}_{2} \mathrm{SO}_{4} \mathrm{pH} 1.6$ during proton irradiation.

Figure 19 Pourbaix diagram for $\mathrm{Au}$ showing areas of thermodynamic stability.

Figure 20 Detailed representation of the Au oxidation / reduction region of the $\mathrm{CV}$ for the sample during irradiation at a proton beam current of $100 \mathrm{nA}$

Figure 21 Detailed representation of the Au oxidation / reduction region of the CV in Figure 19 for all beam currents examined. 


\section{Introduction}

In this investigation Electrochemical Impedance Spectroscopy (EIS) and potentiodynamic polarization curves were used to characterize changes in tungsten, tantalum, stainless steel 304L, and gold samples as a function of beam current at the LANSCE Weapons Neutron Research facility (commonly referred to as the Blue Room). The first three of these materials have obvious applications in spallation neutron sources. Gold was examined in these experiments because the oxide which forms on it is easily reduced. This provides a well characterized sample surface free of oxide. The ability to examine an oxide free surface is important if one wishes to eliminate beam interaction with the passive film as one of the possibilities for the observed effects of proton irradiation. The native oxide which forms on all metals (except gold) is thin (less than $100 \times 10^{-10}$ meters), amorphous (good short range order, poor long range order) and to some extent hydrated. The electronic conductivity of most oxides is poor ranging from semiconductor $\left(\mathrm{Fe}_{2} \mathrm{O}_{3}, \mathrm{TiO}_{2}\right.$, $\mathrm{PbO})$ to insulator $\left(\mathrm{Al}_{2} \mathrm{O}_{3}, \mathrm{Ta}_{2} \mathrm{O}_{5}\right)$, though redox reactions can occur readily on most metal oxides via electron tunneling as the oxide layer is thin.

\section{Background}

Effect of Proton Irradiation on Corrosion There have been very few studies on the corrosion behavior of materials in high energy particle beam environments. Simnad and Smoluchowski investigated the effects of a $260 \mathrm{MeV}$ proton beam on the open circuit potential (OCP) of a tungsten target[1]. The sample was a $0.3 \mathrm{~mm}$ diameter wire which was annealed at $900^{\circ} \mathrm{C}$ and degreased before being placed in the irradiation cell. Electrode potentials were measured during irradiation with respect to a saturated calomel cell by means of a vacuum tube potentiometer. The electrolyte was an oxygen-free, saturated $\mathrm{KCl}$ solution. They found for 260 $\mathrm{MeV}$ protons that the OCP of the tungsten sample became more positive at increasing proton fluences as shown in Table 1.

Their interpretation of this result was that the radiation field creates defects at the metal surface which contribute [somehow] to the observed electrode potential increase. They theorize 
that the defects had to be large (dislocation lines, loops, or collapsed vacancy clusters) because isolated vacancies and interstitials would presumably disappear rapidly given their proximity to the surface. In order to test the hypothesis, that defects at the metal surface were responsible for the change in potential, they took a fourth sample, irradiated it, then after the irradiation period annealed it at $900^{\circ} \mathrm{C}$. After the annealing period they measured the electrode potential of the $\mathrm{W}$ sample out-of-beam and found that it had returned to its original value. They concluded that the damage (and the corresponding enhanced corrosion) is reversible and can be "baked out". This assumes, however, that the interaction of the proton beam with the material produces a steady state condition which does not change once the sample is removed from the proton beam.

Table 1 Effect of $260 \mathrm{MeV}$ protons on the open circuit potential of tungsten (from ref. [1]).

\begin{tabular}{|l|c|c|}
\hline Sample Number & $\begin{array}{c}\text { Proton Fluence } \\
\left(\mathbf{p} / \mathbf{c m}^{2}\right)\end{array}$ & $\begin{array}{c}\text { Change in W Potential } \\
(\mathbf{m V})\end{array}$ \\
\hline $\mathbf{0}$ & 0 & 0 \\
\hline $\mathbf{1}$ & $1.8 \times 10^{15}$ & 39 \\
\hline $\mathbf{2}$ & $6.8 \times 10^{15}$ & 47 \\
\hline $\mathbf{3}$ & $2.2 \times 10^{15}$ & 84 \\
\hline
\end{tabular}

A similar study on the proton irradiation of iron[2], addressed metal dissolution rates. The electrolyte was a $\mathrm{pH} 2, \mathrm{HCl}$ solution. It was found for a fluence of $1 \times 10^{16} \mathrm{p} / \mathrm{cm}^{2}$ that the dissolution of the $\mathrm{Fe}_{2} \mathrm{O}_{3}$ layer at the surface of an iron electrode increased from $0.4 \mathrm{mg} / \mathrm{cm}^{2}$ in the absence of irradiation to approximately $1.4 \mathrm{mg} / \mathrm{cm}^{2}$ during irradiation.

Investigators have also evaluated the efficacy of corrosion inhibitors in particle accelerator cooling loops[3]. These studies have focused on the addition of hydrazine and benzotriazole at the CERN accelerator to mitigate copper corrosion in the magnet cooling water loops of the Linac. While water quality was improved by both inhibitors (evaluated by the concentration of $\mathrm{Cu}^{++}$in solution), their use was limited to low radiation doses. Because of the high dose rates typical of target blanket cooling loop these inhibitors are not likely to be acceptable. 
Water Radiolysis Radiolysis models $[4,5,6]$ have indicated that both oxidizing and reducing species are produced when water is irradiated with proton, neutron, or gamma radiation. These species are: $\mathrm{H}_{2}, \mathrm{O}_{2}, \mathrm{H}_{2} \mathrm{O}_{2}, \mathrm{OH}, \mathrm{H}, \mathrm{e}_{\text {aq }}^{-}, \mathrm{HO}_{2}, \mathrm{O}_{2}^{-}, \mathrm{HO}_{2}^{-}, \mathrm{OH}^{-}, \mathrm{H}^{+}$. A list of some of the possible decomposition mechanisms for these species and their respective rate constants are presented in Table 2. As indicated by the reaction rate constants, the lifetime of many of these species is short, on the order of milliseconds to microseconds. While these short lived species may be an important consideration in the corrosion mechanism if they are formed at the metal / solution interface of the beam spot (i.e., the Helmholtz layer) they will have little impact on materials "downstream" in the cooling water loop.

Long-lived radiolysis products such as hydrogen peroxide $\left(\mathrm{H}_{2} \mathrm{O}_{2}\right)$ and oxygen $\left(\mathrm{O}_{2}\right)$ are more likely to control the corrosion reaction mechanism of downstream materials. Both of these species are oxidizing species[7] and have lifetimes on the order of days or weeks. Oxidizing species are detrimental as corrosion reactions are generally cathodically limited. That is, anodic and cathodic reactions at the rest potential are in equilibrium (i.e. you can not store charge) and the rate determining step is typically the cathodic reaction. Therefore, an increase in the concentration of an oxidizing species increases the rate determining step in the corrosion reaction and, correspondingly, increases the anodic (dissolution) reaction.

While some valuable insight into the effects of radiolysis products on corrosion rates has been gained through laboratory simulation[8], many of the radiolysis products are short lived and difficult or impossible to reproduce in the absence of a high energy radiation source. Therefore, a method for measuring the corrosion rates of materials in a prototypical cooling water loop is preferable. 
Table 2 Elementary equations showing some of the water radiolysis products formed during irradiation, their decomposition mechanism, rate constant, and activation energy (from ref.7).

\begin{tabular}{|l|c|c|}
\hline \multicolumn{1}{|c|}{ Reaction } & $\begin{array}{c}\text { Rate Constant } \\
(\text { mole sec })^{-1}\end{array}$ & $\begin{array}{c}\text { Activation Energy } \\
(\mathrm{K} \text { cal/mol })\end{array}$ \\
\hline $\mathrm{e}^{-}+\mathrm{H}_{2} \mathrm{O}=\mathrm{H}+\mathrm{OH}^{-}$ & $2.4 \times 10^{10}$ & 3 \\
$\mathrm{e}^{-}+\mathrm{OH}=\mathrm{OH}^{-}$ & $3.0 \times 10^{10}$ & 3 \\
$\mathrm{H}+\mathrm{H}=\mathrm{H}_{2}$ & $1 \times 10^{10}$ & 3 \\
$\mathrm{e}^{-}+\mathrm{HO}_{2}=\mathrm{HO}_{2}^{-}$ & $2 \times 10^{10}$ & 3 \\
$\mathbf{O H}+\mathbf{O H}=\mathbf{H}_{2} \mathbf{O}_{2}$ & $4.5 \times 10^{9}$ & 3 \\
$\mathbf{H}+\mathbf{O H}=\mathbf{H}_{2} \mathbf{O}$ & $\mathbf{2 . 4 \times 1 0 ^ { 1 0 }}$ & 3 \\
$\mathrm{H}+\mathrm{O}_{2}=\mathrm{HO}_{2}$ & $1 \times 10^{9}$ & 3 \\
$\mathrm{OH}^{-}+\mathrm{H}_{2} \mathrm{O}_{2}=\mathrm{HO}_{2}^{-}+\mathrm{H}_{2} \mathrm{O}$ & $1 \times 10^{8}$ & 4.5 \\
$\mathrm{HO}_{2}=\mathrm{O}_{2}^{-}+\mathrm{H}^{+}$ & $8 \times 10^{5}$ & 3 \\
\hline
\end{tabular}

Electrochemical Impedance Spectroscopy Electrochemical Impedance Spectroscopy (EIS) is a powerful non-destructive technique for measuring the corrosion rates of metals in aqueous environments $[9,10,11]$. In EIS a small sinusoidal voltage perturbation $(10-30 \mathrm{mV})$ is applied across the sample interface as a function of frequency. By measuring the transfer function of the applied ac voltage perturbation and the ac current response of the material, an impedance results $(\mathrm{Z} \omega=\mathrm{V} \omega / \mathrm{I} \omega)$. In the simplest sense, at low frequencies the material behaves as a resistor and $\mathrm{Z} \omega=\left(\mathrm{R}_{\mathrm{sol}}+\mathrm{R}_{\mathrm{pol}}\right)$ where $\mathrm{R}_{\mathrm{sol}}$ is the ohmic resistance due to the solution and $\mathrm{R}_{\mathrm{pol}}$ is the polarization resistance of the metal sample. At high frequencies, the material behaves as a capacitor and, therefore, offers no resistance to current. As a result $Z \omega=R_{\text {sol }}$. By measuring $Z \omega$ over a wide frequency range the solution resistance can be subtracted from the polarization resistance. From $R_{p o l}$ the corrosion rate $(C R)$ for a sample can be determined from the relationship: $C R=A\left(1 / R_{p o l}\right)$ where $\mathbf{A}$ is a constant.

This description of EIS assumes that the system being investigated behaves as a simple Randles' circuit. This circuit may be characterized by its electrical equivalents: a series resistor representing the geometric solution resistance which acts in series with a combination parallel resistance and capacitance representing the charge transfer and double layer capacitance 
respectively. Most electrochemical systems, however, do not behave in this manner. This is no a drawback, rather, an advantage of EIS. Specifically, it allows the investigator to characterize many of the properties of an electrochemical system in addition to the charge transfer resistance and the double layer capacitance.

\section{Experimental}

Experiments were conducted in the Weapons Neutron Research facility at LANSCE. This facility provided access to a proton beam for a conventional three electrode electrochemical cell (discussed below). The proton beam measured approximately $1-2 \mathrm{~cm}$ in diameter $(\sigma=4-8 \mathrm{~mm})$ and had an energy of $800 \mathrm{MeV}$. The proton beam had a characteristic macropulse repetition rate of 20 $\mathrm{Hz}$ and a gate length of 625 microseconds (Figure 1). Beam currents were controlled by varying the spacing between each micropulse (and therefore the number of micropulses) in the gate. Nominally, the currents varied between 50 and $500 \mathrm{nA}$ (Figure 1).

Two sample configurations were used in these experiments. The first sample was fabricated from a $99.96 \%$ tungsten rod, 1/8" in diameter (Figure 2a). Tungsten was the only material used in this configuration. The flattened region of the half-round sample faced the beam and measured $2 \mathrm{~cm} \times 0.31 \mathrm{~cm}$. The total surface area exposed to solution measured $1.7 \mathrm{~cm}^{2}$. The sample volume exposed to the proton beam was approximately equal to $0.614 \mathrm{~cm}^{3}$. No masking of the sample was employed to minimize solution contamination from radiation damage and crevicing. To eliminate the effects of heating and to minimize radiation exposures, metal foils were used for all tantalum, SS304, Au, and some W experiments. Each foil measured approximately 1 $\mathrm{cm}$ in width by $2 \mathrm{~cm}$ in length. Sample thickness was dependent upon the material and varied from $0.1 \mathrm{~mm}(\mathrm{~W})$ to $0.3 \mathrm{~mm}(\mathrm{Au})$. Approximately $2 \mathrm{~cm}^{2}$ of any given sample were exposed to solution during the experiments. These samples served as both the proton beam target and the working electrode (WE) for our electrochemical measurements. 


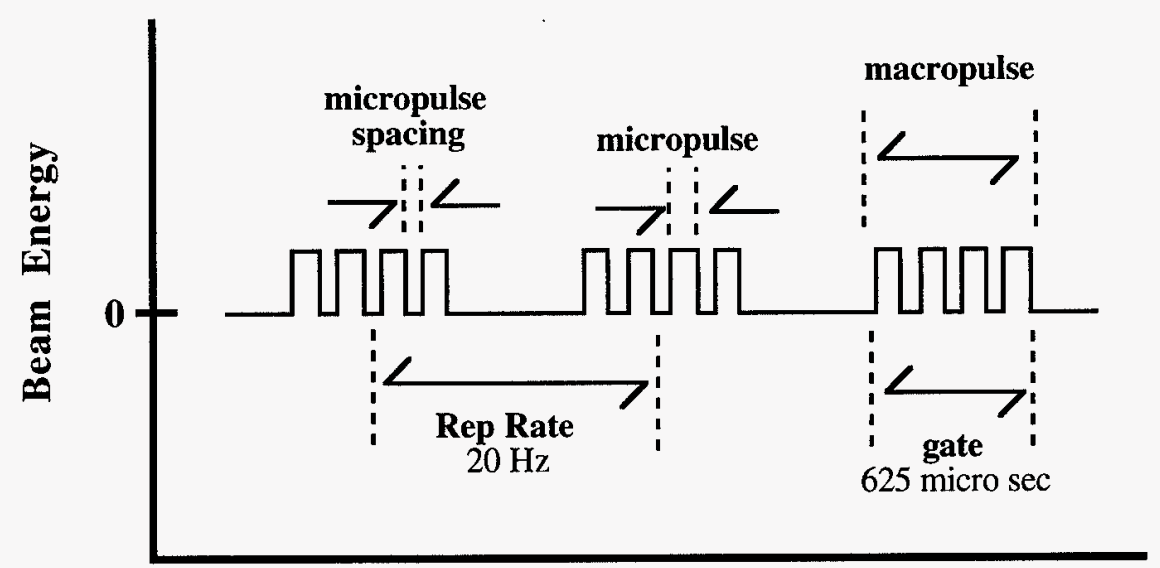

Time

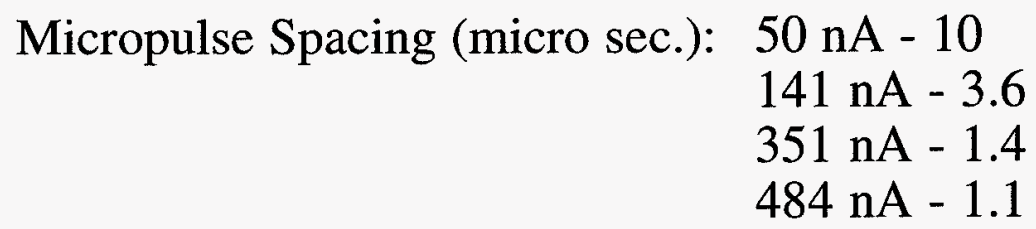

Figure 1 Diagram depicting proton beam profile at the Weapons Neutron Research facility at LANSCE. The spacing between each micropulse is also given with respect to the beam current.

The three electrode electrochemical cell used in these experiments is shown in Figure $2 \mathrm{~b}$. In addition to the $\mathrm{W}$ target, this cell also contained a platinum mesh counter electrode (CE) and a Saturated Calomel (SCE) reference electrode (RE). It has been reported that SCE maintains its stability after gamma irradiation at integrated dose rates of $1 \times 10^{4}$ to $9 \times 10^{8}$ rads[12]. Here, some discoloration of the plastic parts in the SCE (Vicor tip, shrink tubing, SCE body) was noted after the irradiation period but no structural damage to them or the cotton wadding was observed. The test solutions consisted of $0.1 \mathrm{M}$ sodium chloride $(\mathrm{NaCl})$ and sulfuric acid $\left(\mathrm{H}_{2} \mathrm{SO}_{4}\right) \mathrm{pH}$ 1.6. These solutions were made from reagent grade chemicals and deionized water. In all experiments the test solution was pumped through the cell and across the sample at a rate of $1.02 \mathrm{~L} / \mathrm{min}$ with a peristaltic pump from a 1 gallon reservoir. This was done to minimize build up of radiolysis products and heating of the target due to energy deposition from the proton beam. The maximum cell temperature recorded during the irradiation was $26.0^{\circ} \mathrm{C}$. Room temperature was $24.5^{\circ} \mathrm{C}$. 

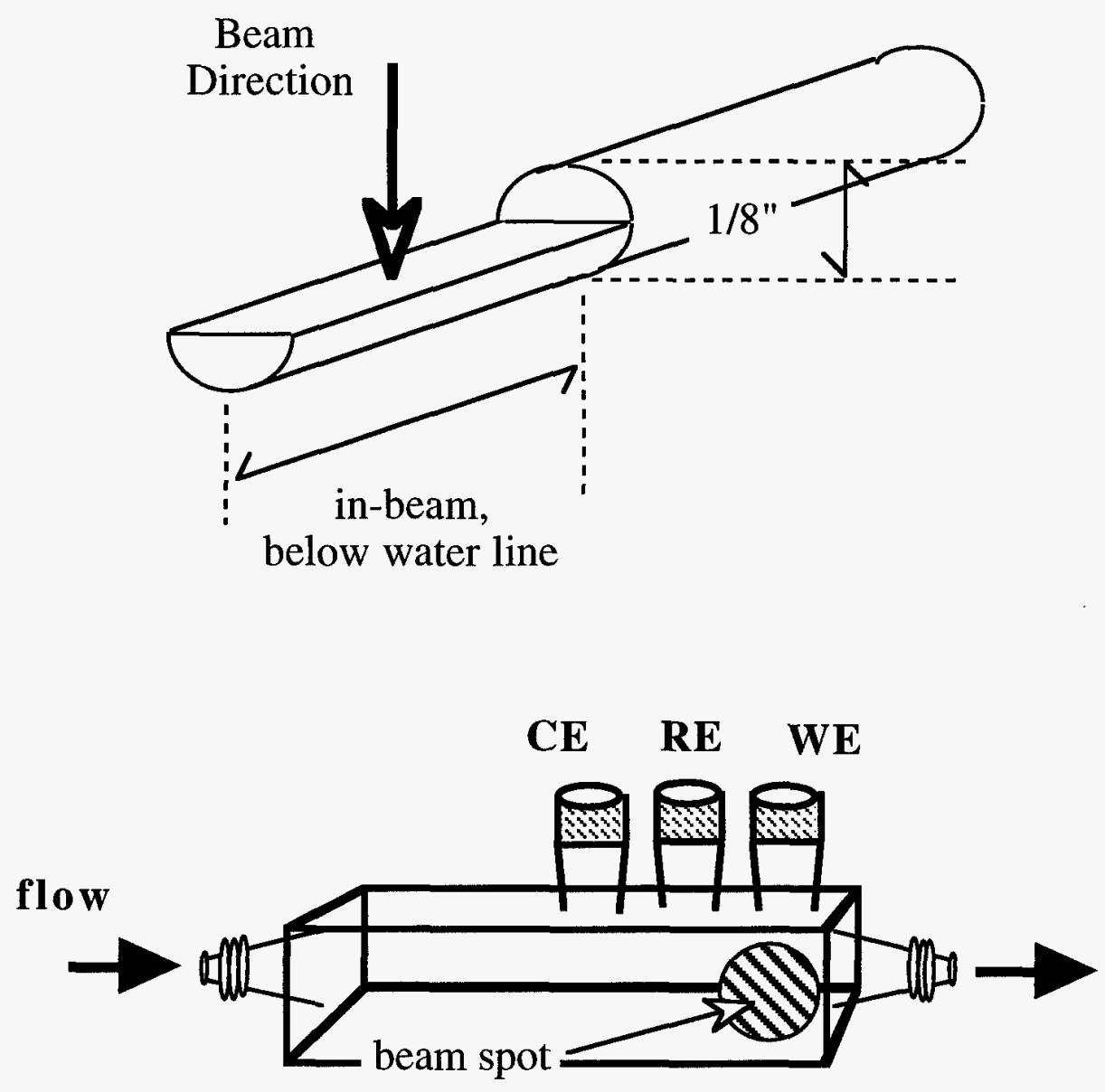

Figure 2 Diagrams depicting a) "half-round" tungsten target and b) electrochemical flow cell used in WNR irradiation experiments. WE denotes working electrode (W target), RE denotes reference electrode (SCE), and CE denotes counter electrode (platinum mesh).

All electrochemical measurements were performed with a floating ground system. This was done to eliminate errors that may have been introduced by ground loops. EIS measurements were generated at the open circuit potential (OCP) and at applied anodic potentials over the frequency range of $10 \mathrm{~K} \mathrm{~Hz}$ to $0.001 \mathrm{~Hz}$. In these experiments, 10 data points were collected per decade of frequency. Potentiodynamic polarization curves were generated at a scan rate of 0.2 $\mathrm{mV} / \mathrm{s}$. This scan rate was chosen to ensure a steady state current as well as to ensure efficient use of beam time. Little difference was observed between laboratory experiments which employed scan rates of $0.2 \mathrm{mV} / \mathrm{sec}$ and $0.05 \mathrm{mV} / \mathrm{sec}$ which may more closely approximate steady state. 


\section{Results and Discussion}

Effect of Beam Current on the Open Circuit Potential The OCP for tungsten in the WNR flow cell as a function of time is shown in Figure 3. When the proton beam was turned on ( $2 \mathrm{nA}$ beam current) to align the cell with the beam centerline a small positive shift in the OCP from its steady state value of $-0.305 \mathrm{~V} \mathrm{SCE}$ to a value of $-0.295 \mathrm{~V}$ SCE was observed. After alignment, the OCP began to decrease towards its original value. As shown in Figure 3, soon after alignment the proton beam was turned on at $50 \mathrm{nA}$. Correspondingly, a positive $45 \mathrm{mV}$ increase in the OCP was observed. While the OCP for $\mathrm{W}$ shifted to more positive potentials with increasing beam current, the OCP was not proportional to beam current and appeared to plateau around $-0.220 \mathrm{~V} \mathrm{SCE}$ (Figure 4).

Similar trends in OCP were also observed for Ta and SS 304 in $\mathrm{H}_{2} \mathrm{SO}_{4}$. However, as shown in Figure 5, the change in OCP was as large as $0.20 \mathrm{~V}$ for these materials at $100 \mathrm{nA}$ of beam current. In comparison, the $\mathrm{OCP}$ of $\mathrm{W}$ in $\mathrm{NaCl}$ changed by only $60 \mathrm{mV}$ at a proton beam current of $500 \mathrm{nA}$. While a positive shift in the OCP is consistent with the formation of radiolysis products such as hydrogen peroxide, the rapid response of the system from beam-off to beam-on abruptly followed by a plateau in the OCP is not consistent with a steadily increasing concentration of radiolysis products. Moreover, this trend is also consistent with a change in the oxide surface state, and therefore, a change in OCP is not necessarily evidence of the controlling mechanism . 


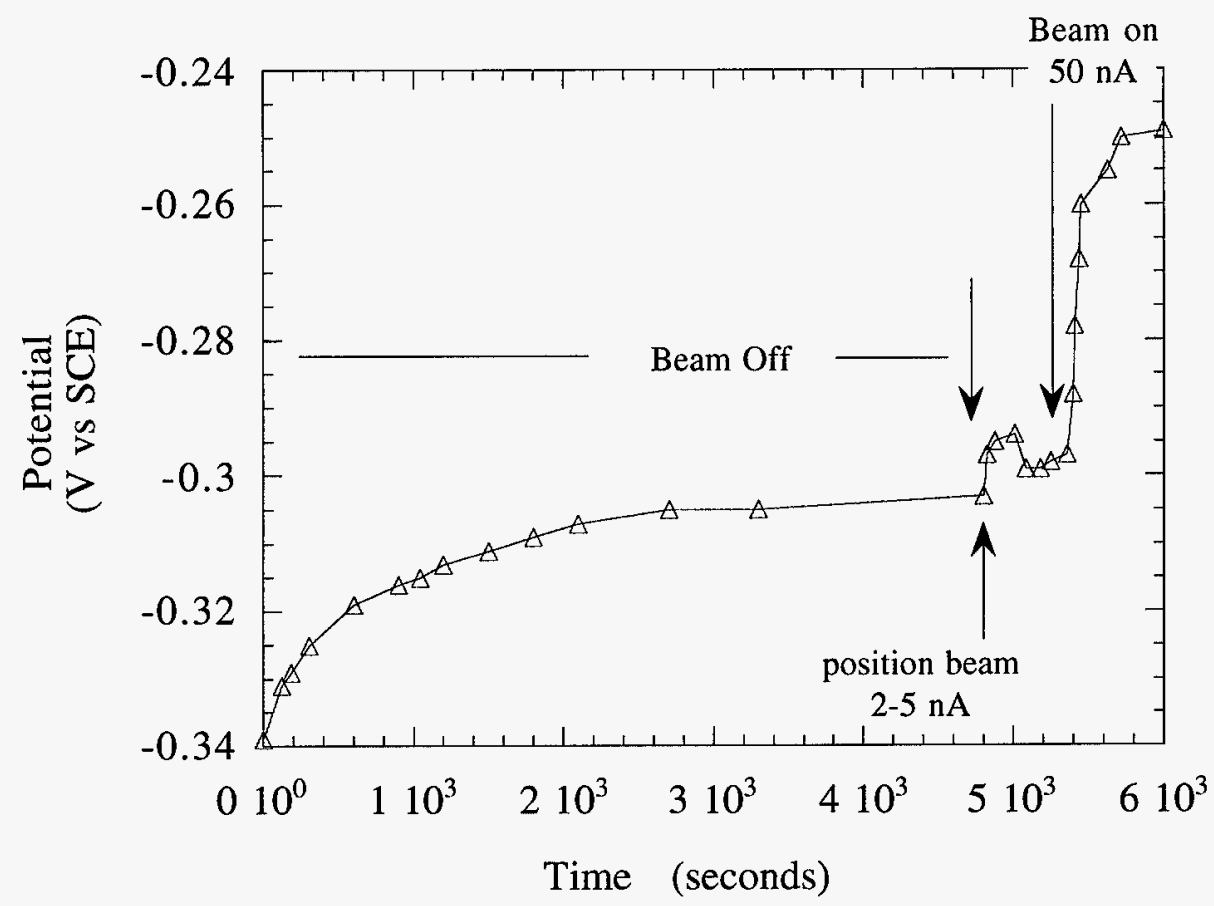

Figure 3 Open circuit potential for $\mathrm{W}$ in flow cell with $0.1 \mathrm{M} \mathrm{NaCl}$. Plot shows pre-beam values, change in OCP during positioning of beam, and steady state irradiation at $50 \mathrm{nA}$.

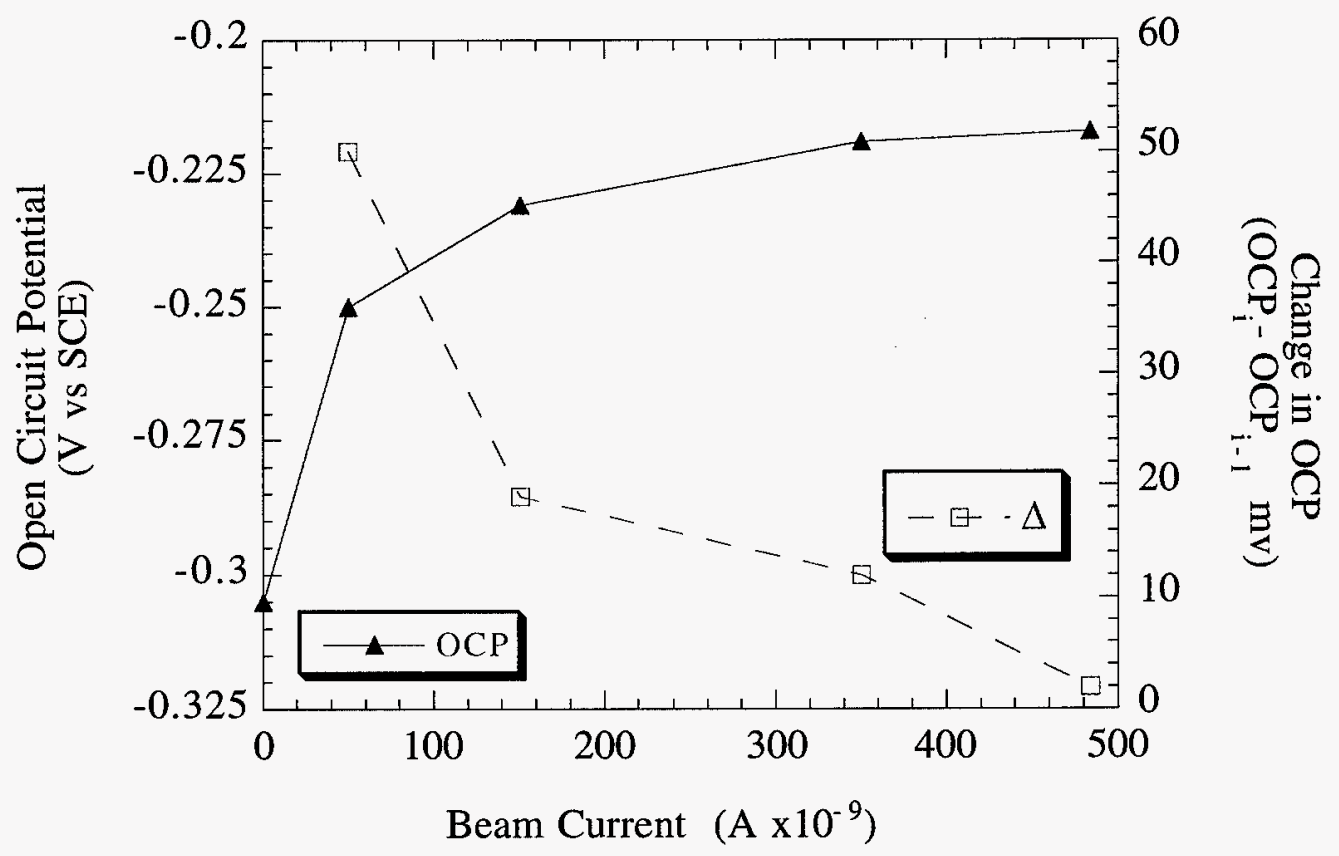

Figure 4 Open circuit potential for $\mathrm{W}$ in $0.10 \mathrm{M} \mathrm{NaCl}$ as a function of proton beam current. Plot also shows change in open circuit potential from previous value as a function of beam current. 


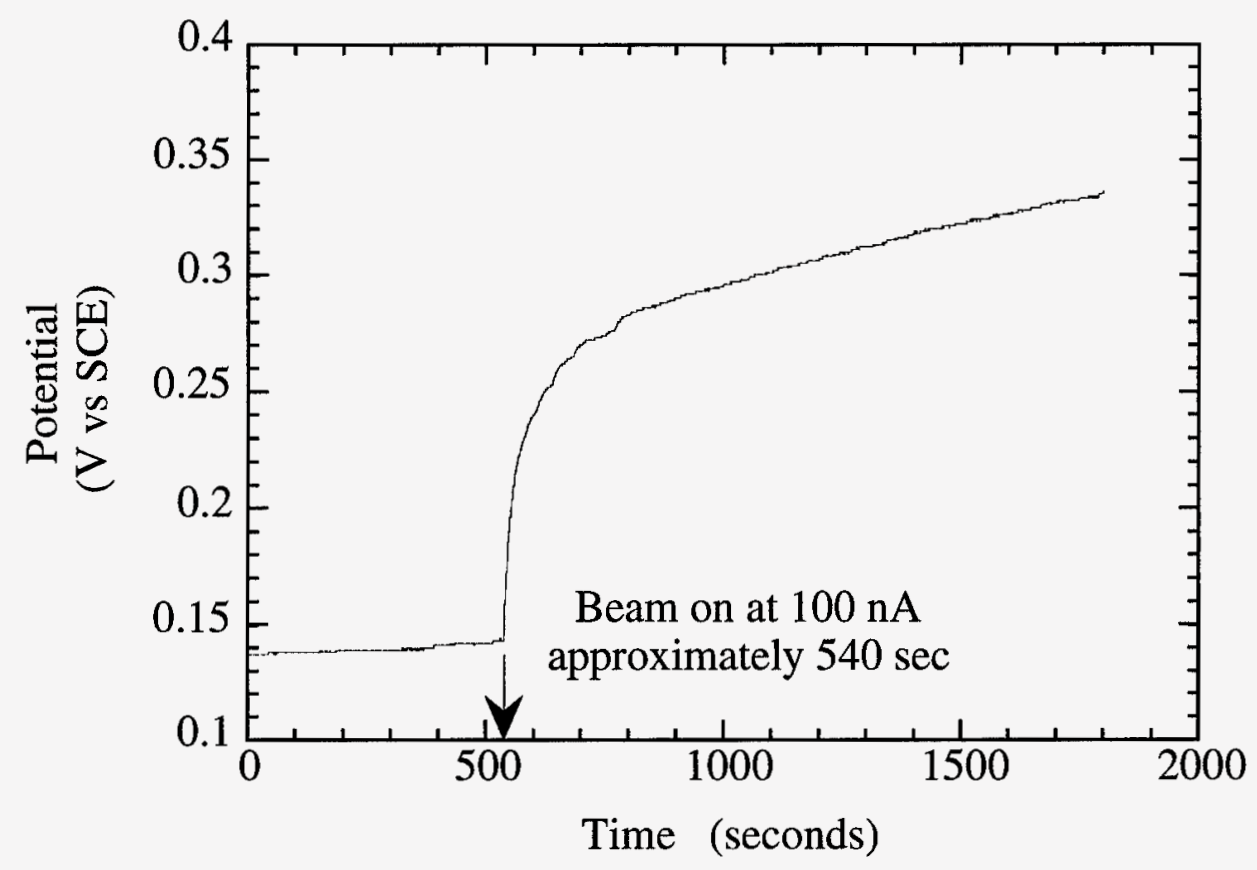

Figure 5 Open circuit potential for SS304 in flow cell with $\mathrm{H}_{2} \mathrm{SO}_{4}$. Plot shows pre-beam values and value during irradiation at $100 \mathrm{nA}$.

Effects of Proton Irradiation on $W$ To distinguish between increased cathodic reaction kinetics (which will result from hydrogen peroxide production) and radiation "enhanced" anodic reaction kinetics, EIS experiments for $\mathrm{W}$ were conducted at an applied anodic potential of $0.0 \mathrm{~V}$ SCE. This potential is near the mass transport limited dissolution rate for $\mathrm{W}$ in $0.10 \mathrm{M} \mathrm{NaCl}$. Typical EIS data before the beam was turned on and for beam currents of $141 \mathrm{nA}$ and $484 \mathrm{nA}$ are presented in Figure 6 in the form of Nyquist plots. These graphs plot the imaginary impedance as a function of the real component of the impedance. Recall that impedance, $Z(\omega)$, has both real and imaginary components:

$$
\mathrm{Z}(\omega)=\mathrm{Z}(\omega)_{\text {real }}+\mathrm{jZ}(\omega)_{\mathrm{imag}}
$$

where $Z_{\text {real }}$ and $Z_{\text {imag }}$ are the real and imaginary components respectively and $j=(-1)^{1 / 2}$. In Figure 6 $Z_{\text {real }}$ is represented by $Z^{\prime}$ and the $Z_{\text {imag }}$ by $Z^{\prime \prime}$. 
As seen in Figure 6, there is a precipitous decrease in low frequency impedance of the tungsten target as beam current is increased. It has been shown by Armstrong, et al.[13] that the dissolution mechanism for $\mathrm{W}$ is mass transport limited at the solution / electrode interface. The equivalent circuit model for this behavior is presented in Figure $7 \mathrm{a}$ where: $R_{c t}$ is the impedance associated with the charge transfer reaction, $\mathrm{C}_{\mathrm{dl}}$ is the capacitance associated with the double layer and $\mathrm{W}$ is a diffusional impedance (also referred to as a Warburg type impedance[14,15]). Having extended our measurements to lower frequencies than those used by Armstrong we are able to replace the Warburg impedance with the parallel $\mathrm{RC}$ combination as shown in Figure $7 \mathrm{~b}$ where: $\mathrm{R}_{\mathrm{as}}$ represents the discharge of an adsorbed species and $\mathrm{C}_{\text {as }}$ capacitance associated with an absorbed

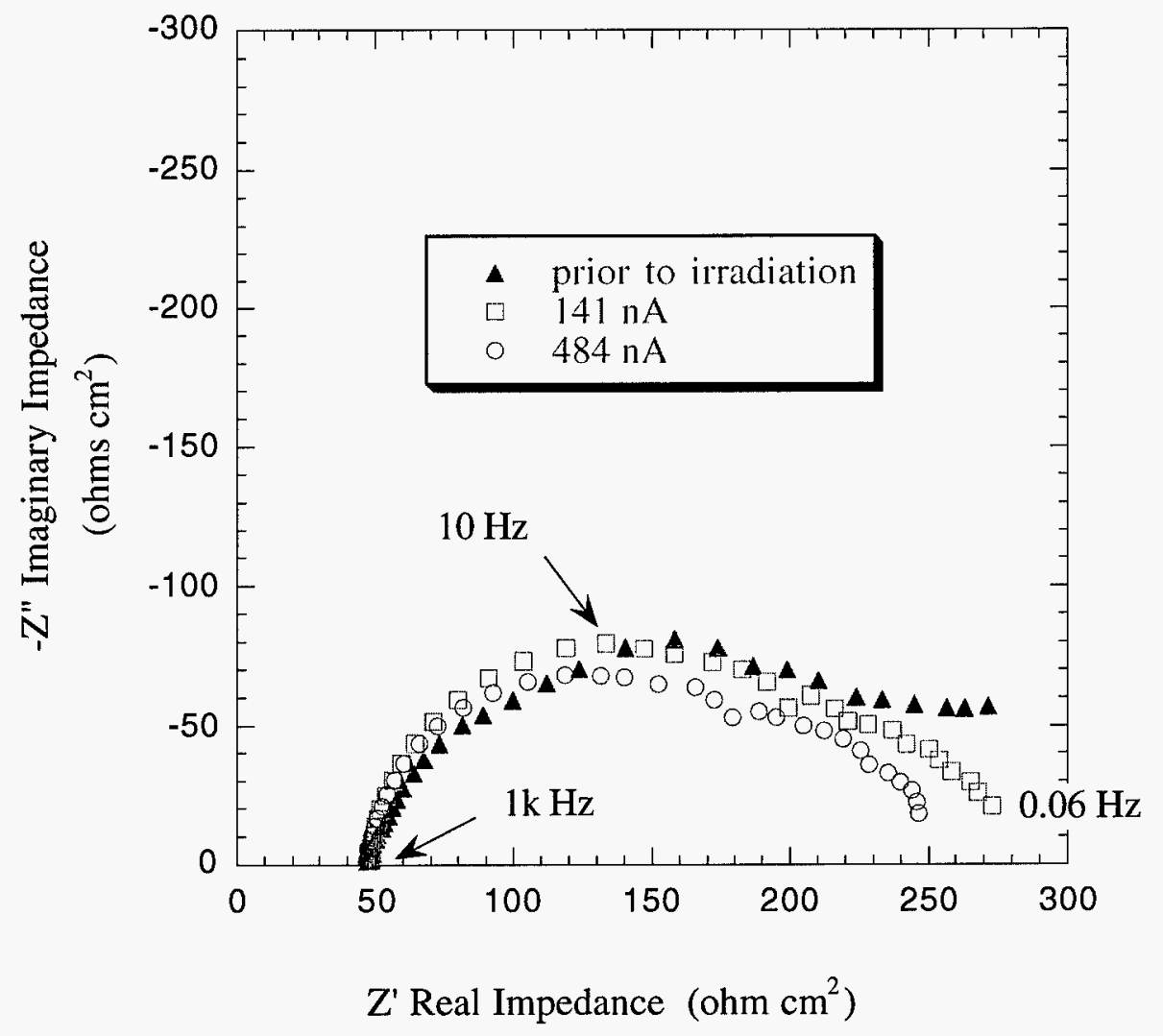

Figure 6 Nyquist plots for the WNR tungsten target in $0.10 \mathrm{M} \mathrm{NaCl}$ as a function of proton beam current. 
intermediate[16,17]. $C_{a s}$ is often referred to as an adsorption psuedocapacitance[18]. $R_{a s}$ and $C_{a s}$ are not to be confused with traditional fixed resistive and capacitive elements however, as their impedance becomes infinite in magnitude at zero frequency. A complex non-linear least squares fit of the EC in Figure $7 \mathrm{~b}$ to the data in Figure 6 (484 nA data) is presented in Figure 8. As seen in this figure, good agreement between the model and this EC exist. Table 3 presents a summary of $\mathrm{R}_{\mathrm{as}}$ and $\mathrm{R}_{\mathrm{ct}}$ for all beam currents.
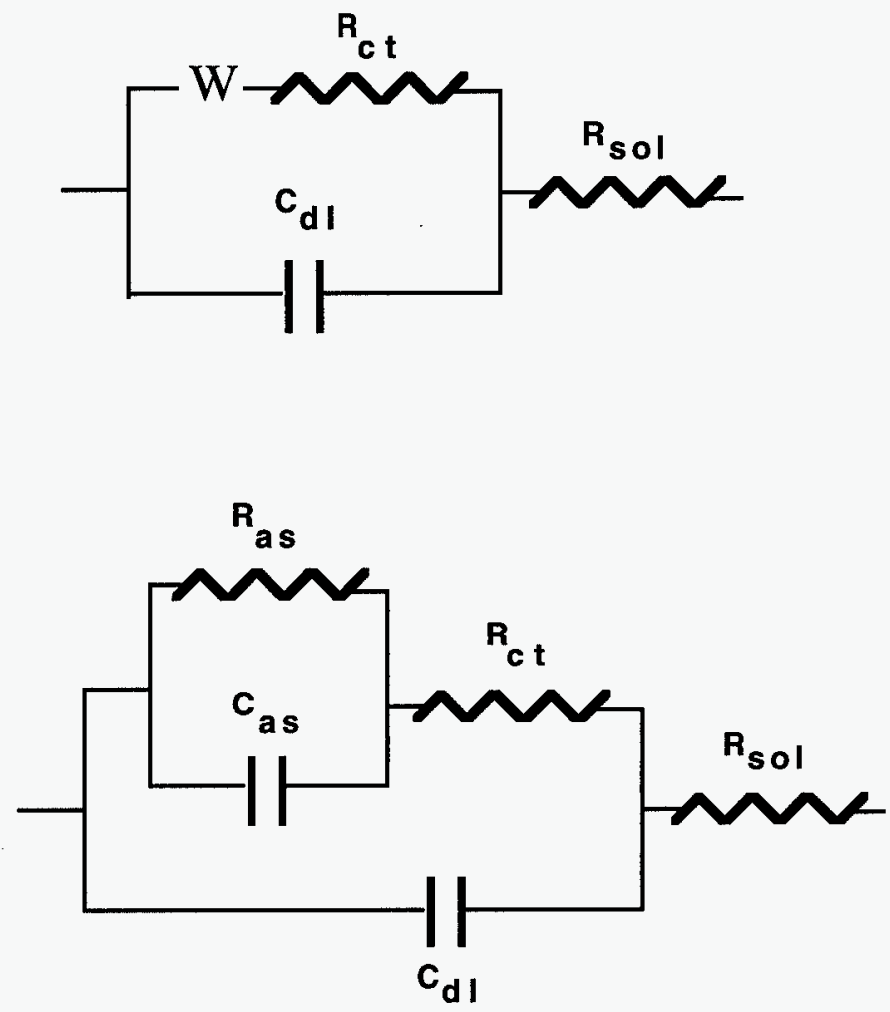

Figure 7 Electrical equivalent circuit representing the tungsten corrosion system where a) $R_{c t}$ represents the charge transfer resistance (inversely proportional to metal dissolution rate), $\mathbf{C}_{\mathrm{dl}}$ represents the double layer capacitance, $R_{\text {sol }}$ represents the geometric solution resistance, and $\mathrm{W}$ represents a Warburg type diffusional impedance; in $b) R_{a s}$ represents the resistance of the an adsorbed intermediate and $\mathrm{C}_{\mathrm{as}}$ represents an adsorption psuedocapacitance. 


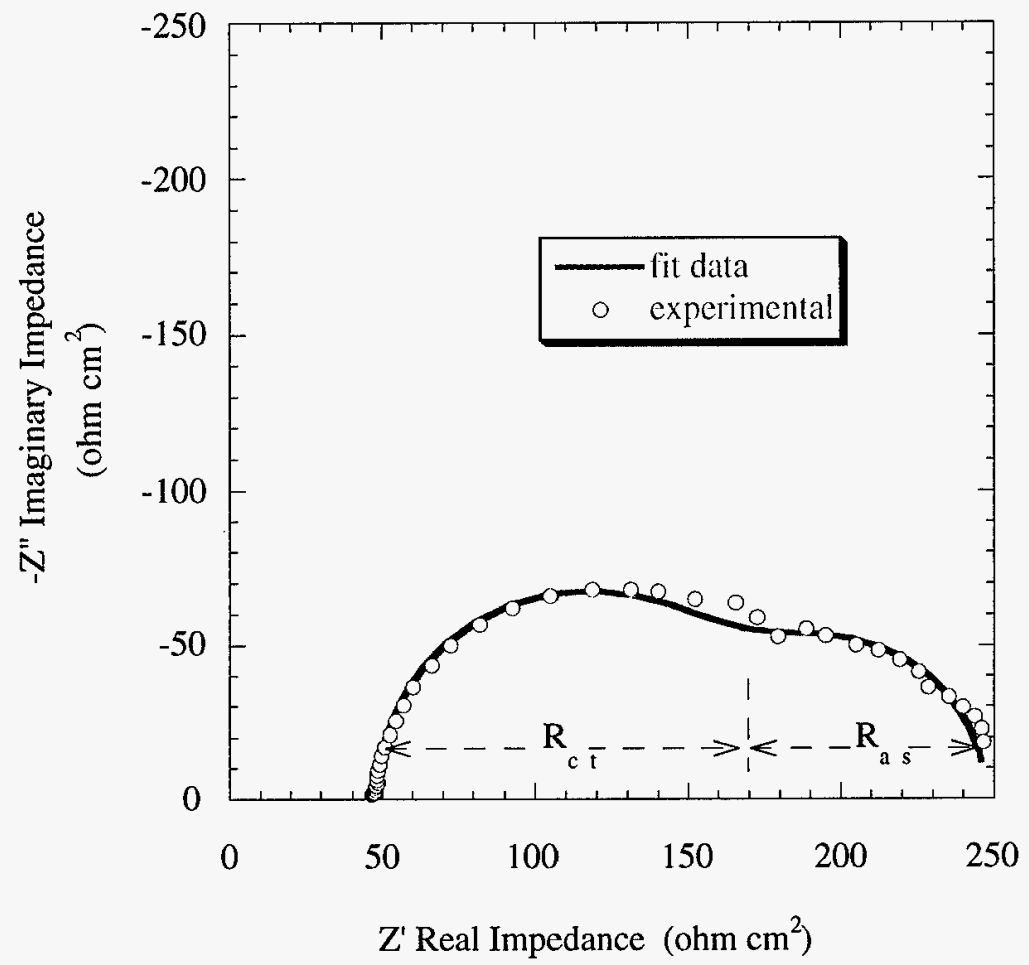

Figure 8 Nyquist plot showing the tungsten target in $0.10 \mathrm{M} \mathrm{NaCl}$ during irradiation at 484 $\mathrm{nA}$ and the fitted data based on the EC presented in Figure 7. As shown in this figure, the high frequency time constant was attributed to the charge transfer resistance while the low frequency time constant was attributed to an adsorbed intermediate.

Table 3 Curve fit data for the WNR tungsten target in $0.10 \mathrm{M} \mathrm{NaCl}$ as a function of beam current.

\begin{tabular}{l|c|c|}
$\begin{array}{l}\text { Beam Current } \\
\mathbf{n A}\end{array}$ & $\begin{array}{c}\mathbf{R}_{\mathbf{c t}} \\
\mathbf{o h m} \mathbf{~ c m}^{\mathbf{2}}\end{array}$ & $\begin{array}{c}\mathbf{R}_{\mathbf{a s}} \\
\mathbf{o h m ~}_{\mathbf{~ c m}}\end{array}$ \\
\hline pre-irradiation & 174 & diffusion \\
\hline $\mathbf{5 0}$ & 146 & 89 \\
\hline $\mathbf{1 5 1}$ & 139 & 84 \\
\hline $\mathbf{3 5 0}$ & 123 & 82 \\
\hline $\mathbf{4 8 4}$ & 119 & 80 \\
\hline $\mathbf{1 ~ h r}$ post & 140 & 88 \\
\hline $\mathbf{1 2} \mathbf{~ h r}$ post & 178 & 95
\end{tabular}


The enhanced dissolution rates observed during in-beam EIS experiments in $0.1 \mathrm{M} \mathrm{NaCl}$ at applied potentials (Figures 6 and 8) are complemented by potentiodynamic polarization curves for W generated during proton irradiation. In-beam and out-of-beam potentiodynamic polarization curves for $\mathrm{W}$ in $\mathrm{NaCl}$ pH 5.2 are presented in Figure 9. As shown in this figure both the corrosion rate (dissolution rate at the $\mathrm{OCP}$ ) and the dissolution rate at applied anodic potentials increase in the presence of proton irradiation. This result reinforces the finding from EIS measurements that dissolution rate increases with increasing proton fluence.

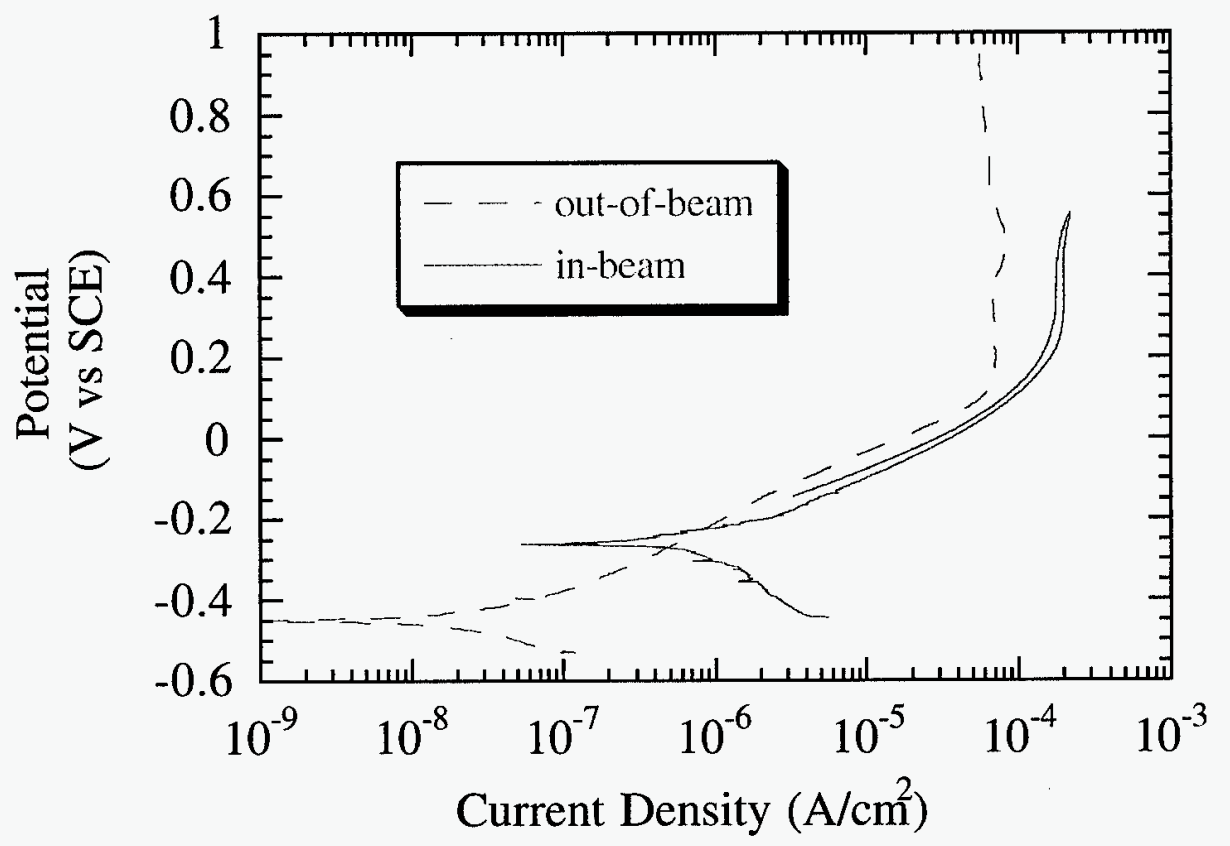

Figure 9 Potentiodynamic polarization curves for $\mathrm{W}$ in $0.1 \mathrm{M} \mathrm{NaCl} \mathrm{pH} 5.2$ for a sample during irradiation at a proton beam current of $100 \mathrm{nA}$ (in-beam) and a sample not exposed to irradiation (out-of-beam).

EIS data as a function of proton beam current for $\mathrm{W}$ in $\mathrm{H}_{2} \mathrm{SO}_{4}(\mathrm{pH} 1.6)$ are presented in Figure 10. Data in this experiment were collected at an applied anodic potential of $+0.225 \mathrm{~V} \mathrm{SCE}$. As seen in this figure, a small decrease in the charge transfer resistance was observed with increasing beam current. As $\mathrm{W}$ is passive in this solution at applied anodic potentials, this increase is associated with an increase in passive current density (i.e. passive dissolution rate). To confirm 
this, potentiodynamic polarization curves for $\mathrm{W}$ in $\mathrm{H}_{2} \mathrm{SO}_{4}(\mathrm{pH}=1.6)$ were conducted during proton irradiation (Figure 11). The data were generated during irradiation in a proton beam at a current of $100 \mathrm{nA}$ after the OCP came to steady state in the beam. For comparison, a polarization curve for $\mathrm{W}$ in $\mathrm{H}_{2} \mathrm{SO}_{4} \mathrm{pH} 1.6$ under ambient conditions is also presented in this figure. Both the passive current density $\left(i_{\text {pass }}\right)$ and the corrosion current density ( $i_{\text {corr }}$, proportional to corrosion rate) were found to increase during irradiation; the passive current density by a factor of 2 times. It is also interesting to note the shape of the curve in the $0.0-0.500 \mathrm{~V}$ region is preserved during irradiation. These results verify the EIS observation that charge transfer resistance at applied anodic potentials decreases with increasing proton beam current.

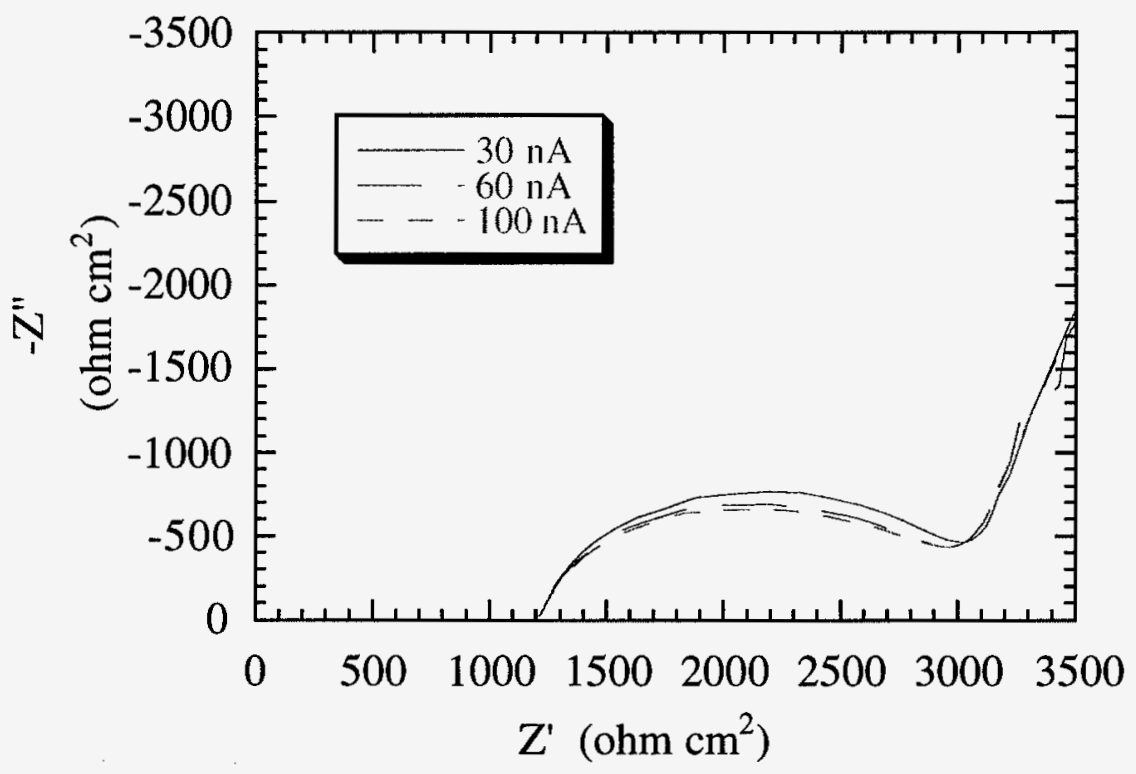

Figure 10 Nyquist plot for $\mathrm{W}$ in $\mathrm{H}_{2} \mathrm{SO}_{4}, \mathrm{pH} 1.6$ at an applied potential of $+0.225 \mathrm{~V} \mathrm{SCE}$. Plot shows the effect of beam current on passive dissolution rate based on the EC presented in Figure 7. 


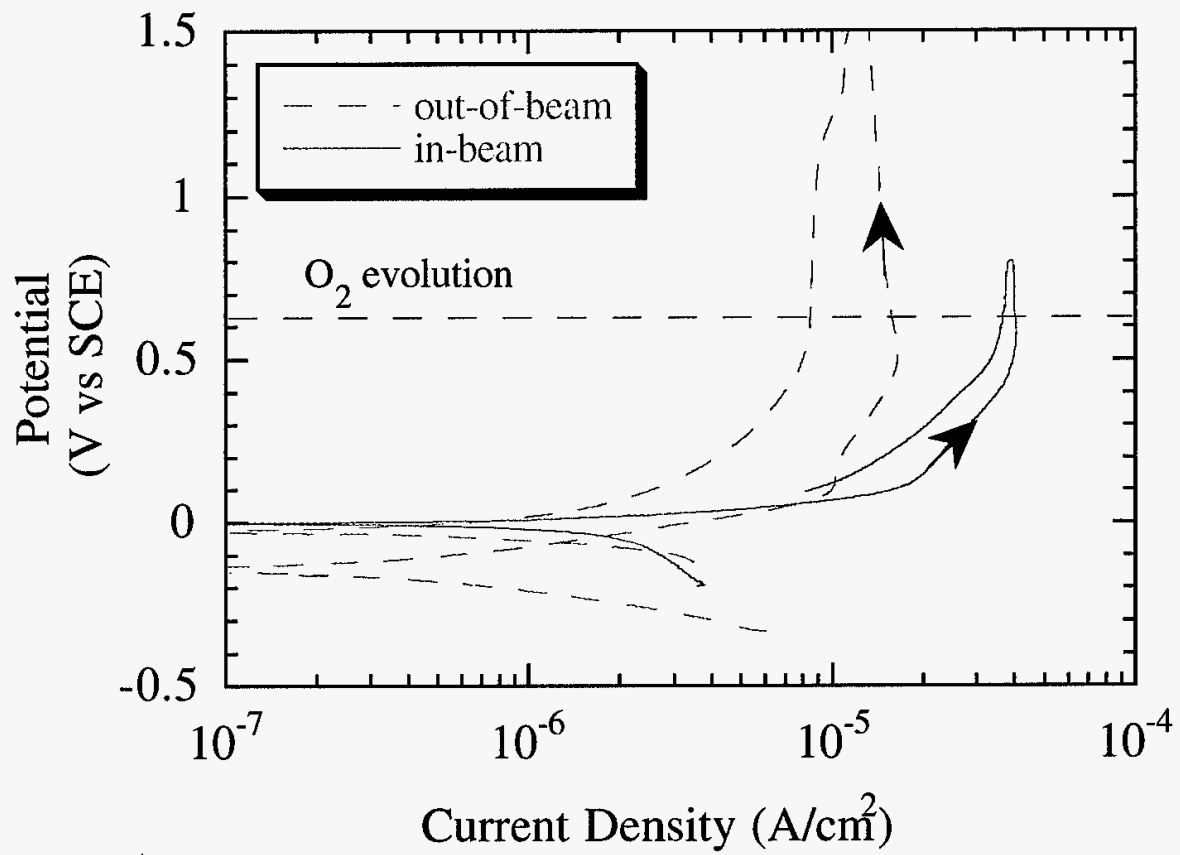

Figure 11 Potentiodynamic polarization curves for $\mathrm{W}_{\text {in }} \mathrm{H}_{2} \mathrm{SO}_{4}(\mathrm{pH}=1.6)$ for a sample during irradiation at a proton beam current of $100 \mathrm{nA}$ (in-beam) and a sample not exposed to irradiation (out-of-beam).

Effects of Proton Irradiation on Stainless Steel 304 EIS data for SS304 in $\mathrm{H}_{2} \mathrm{SO}_{4} \mathrm{pH} 1.6$ are presented in Figure 12. Unlike the in-beam experiments for $\mathrm{W}$ above, here the low frequency impedance (associated with dissolution rate) increases with increasing proton beam current. Additional laboratory experiments are necessary to establish the appropriate equivalent circuit model for this data as was done for $\mathrm{W}$ above.

Potentiodynamic polarization curves for SS304 in $\mathrm{H}_{2} \mathrm{SO}_{4} \mathrm{pH} 1.6$ are presented in Figure 13 for a sample during irradiation at a proton beam current of $100 \mathrm{nA}$ (in-beam) and a sample not exposed to irradiation (out-of-beam). Both forward and reverse portions of the curve are presented as indicated by the arrows in this figure. As seen in this figure, the in-beam specimen is associated with a higher OCP than the out-of-beam specimen as described above although the corrosion current density $\left(\mathrm{i}_{\text {corr }}\right.$ ) for the out-of-beam sample appears to be similar to that of the sample at 100nA. Moreover the transpassive potential (approximately 0.78 V SCE) appears to be similar for both the in-beam and out-of-beam samples as does the transpassive current density at any given 


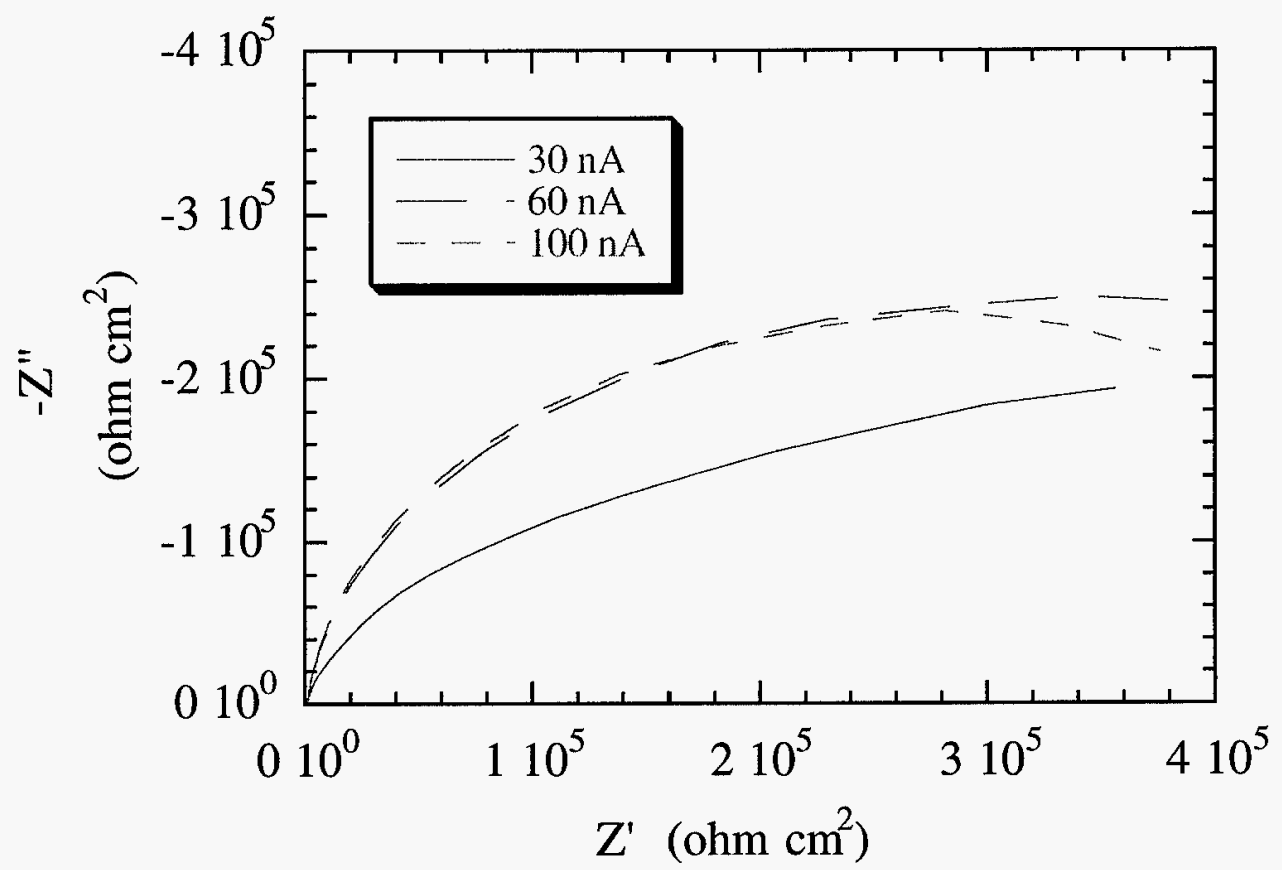

Figure 12 Nyquist plot for SS304 in $\mathrm{H}_{2} \mathrm{SO}_{4}, \mathrm{pH} 1.6$ at an applied potential of $+0.580 \mathrm{~V}$ SCE. Plot shows the effect of beam current on passive dissolution rate.

potential. In addition, the passive current density $\left(i_{\text {pass }}\right)$ for the in-beam appears to be somewhat lower than the out-of-beam sample. Although this difference is small it was reproducible and, in conjunction with the EIS measurements where the charge transfer resistance was found to increase with beam current there is a convincing argument that passive dissolution of SS304 is lowered by interactions with high energy proton irradiation.

During the reverse scan direction in the in-beam polarization curve, a sharp step to lower current densities was observed when the proton beam was shut off. At -0.750 V SCE the current decreased from $9.5 \times 10^{-7} \mathrm{~A} / \mathrm{cm}^{2}$ to a current density of $2.2 \times 10^{-7} \mathrm{~A} / \mathrm{cm}^{2}$ when the beam was shut off at $0.749 \mathrm{~V} \mathrm{SCE}$. This is a $77 \%$ decrease in current density from beam on to beam off. Moreover, the anodic current densities returned to values similar to those measured for the out-of-beam sample. Similar trends were observed in Ta polarization experiments as will be presented below. 


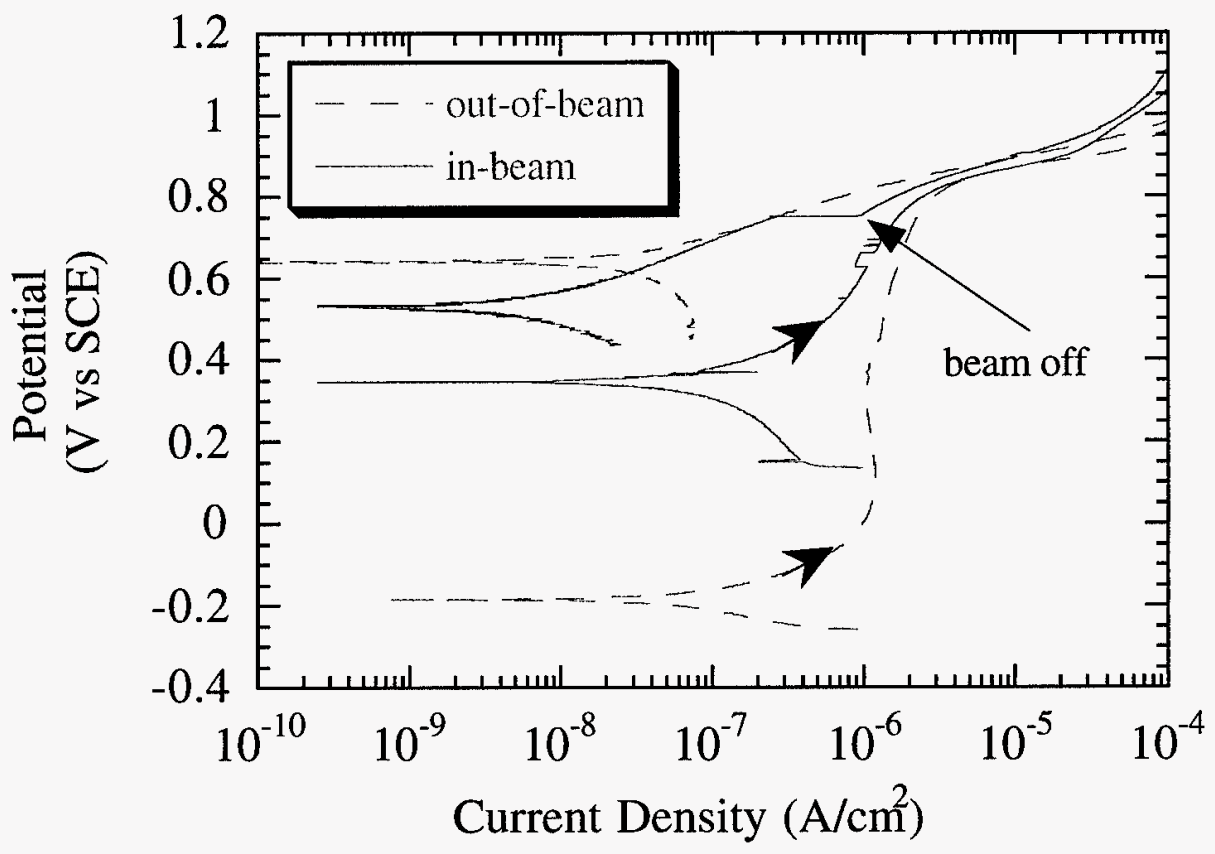

Figure 13 Potentiodynamic polarization curves for $\mathrm{SS}_{0} 04$ in $\mathrm{H}_{2} \mathrm{SO}_{4} \mathrm{pH} 1.6$ for a sample during irradiation at a proton beam current of $100 \mathrm{nA}$ (in-beam) and a sample not exposed to irradiation (out-of-beam).

Additional experiments for SS304 during irradiation were conducted in $0.1 \mathrm{M} \mathrm{NaCl}$. Potentiodynamic polarization curves from these experiments are presented in Figure 14 for samples during irradiation at a proton beam current of $100 \mathrm{nA}$ (in-beam) and not exposed to irradiation (out-of-beam). As can be seen in this figure, while the passive current densities for the two samples are comparable, the corrosion current density is somewhat greater for the in-beam sample. In addition, the pitting potential $\left(\mathrm{E}_{\text {pit }}\right)$ for the in-beam sample is $0.662 \mathrm{~V}$ while the mean value for 3 out-of-beam samples was $0.495 \mathrm{~V}+/-37 \mathrm{mV}$. This is an increase of approximately $170 \mathrm{mV}$, a value which is $4.6 \sigma$ over the mean out-of-beam value. While these results are preliminary, it is an indication that SS304 is less susceptible to pitting attack during irradiation. In comparison, Sikora et al. found that the pitting potential for SS304 could be increased by $60 \mathrm{mV}$ during photon irradiation as compared to samples not exposed to light[19]. It was determined (via Mott Schottky plots) that the increase in pitting potential resulted from a change in the conductivity of the passive 


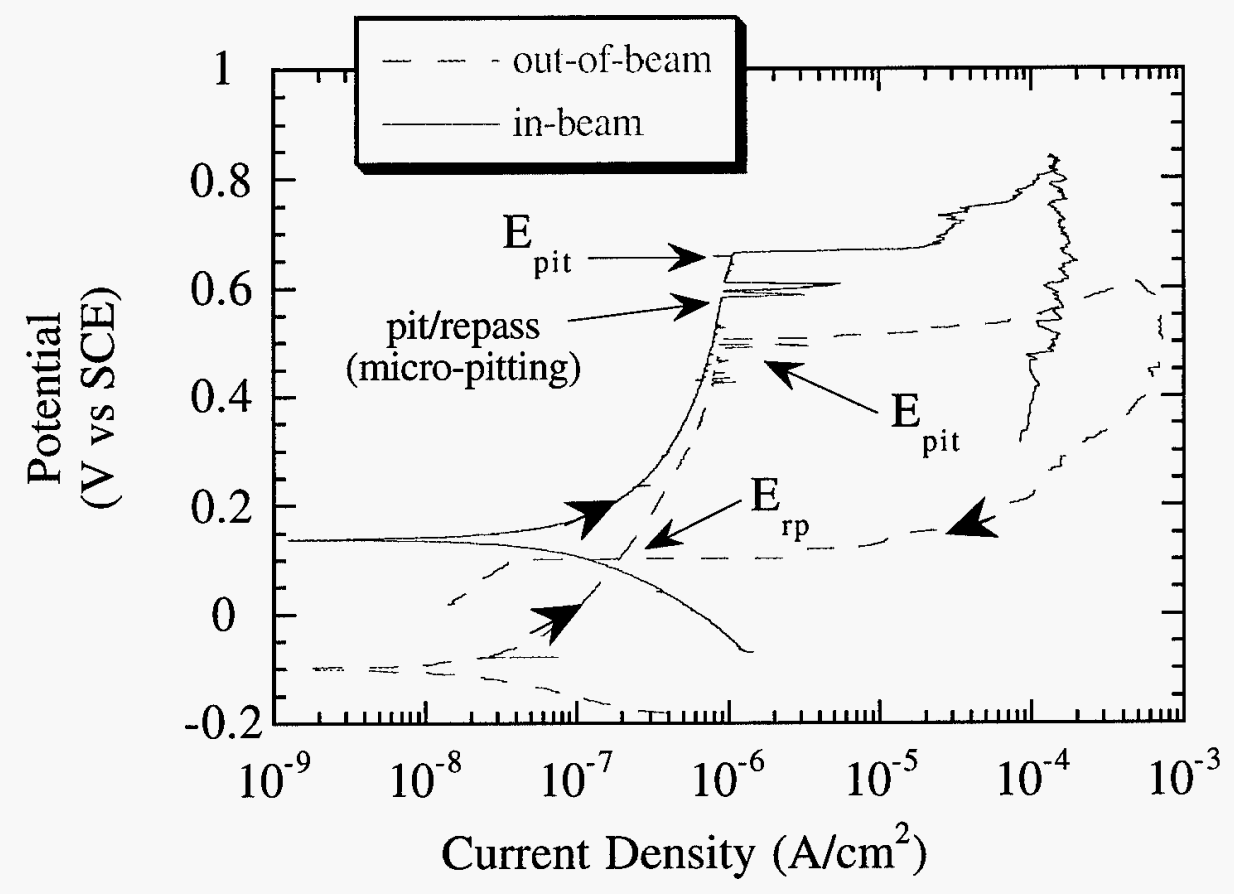

Figure 14 Potentiodynamic polarization curves for SS304 in $0.1 \mathrm{M} \mathrm{NaCl}$ for a sample during irradiation at a proton beam current of $100 \mathrm{nA}$ (in-beam) and a sample not exposed to irradiation (out-of-beam).

oxide on SS304. It is also interesting to note that the OCP of the in-beam sample is approximately $50 \mathrm{mV}$ more positive than the repassivation potential $\left(\mathrm{E}_{\mathrm{rp}}\right)$ for the out-of-beam sample.

Effects of Proton Irradiation on Tantalum EIS data for $\mathrm{Ta}$ in $\mathrm{H}_{2} \mathrm{SO}_{4} \mathrm{pH} 1.6$ are presented in Figure 15. Unlike the in-beam experiments for $\mathrm{W}$ above, here the low frequency data (associated with dissolution rate) increase with increasing proton beam current. A similar trend was observed for SS304 during irradiation. Further laboratory experiments are necessary to establish the appropriate equivalent circuit model for this data as was done for $\mathrm{W}$ above.

Potentiodynamic polarization curves for $\mathrm{Ta}$ in $\mathrm{H}_{2} \mathrm{SO}_{4} \mathrm{pH} 1.6$ are presented in Figure 16 for a sample during irradiation at a proton beam current of $100 \mathrm{nA}$ (in-beam) and a sample not exposed to irradiation (out-of-beam). As seen in this figure, the in-beam specimen is associated with an OCP which is $0.400 \mathrm{~V}$ higher than the out-of-beam specimen as described above. In addition, 


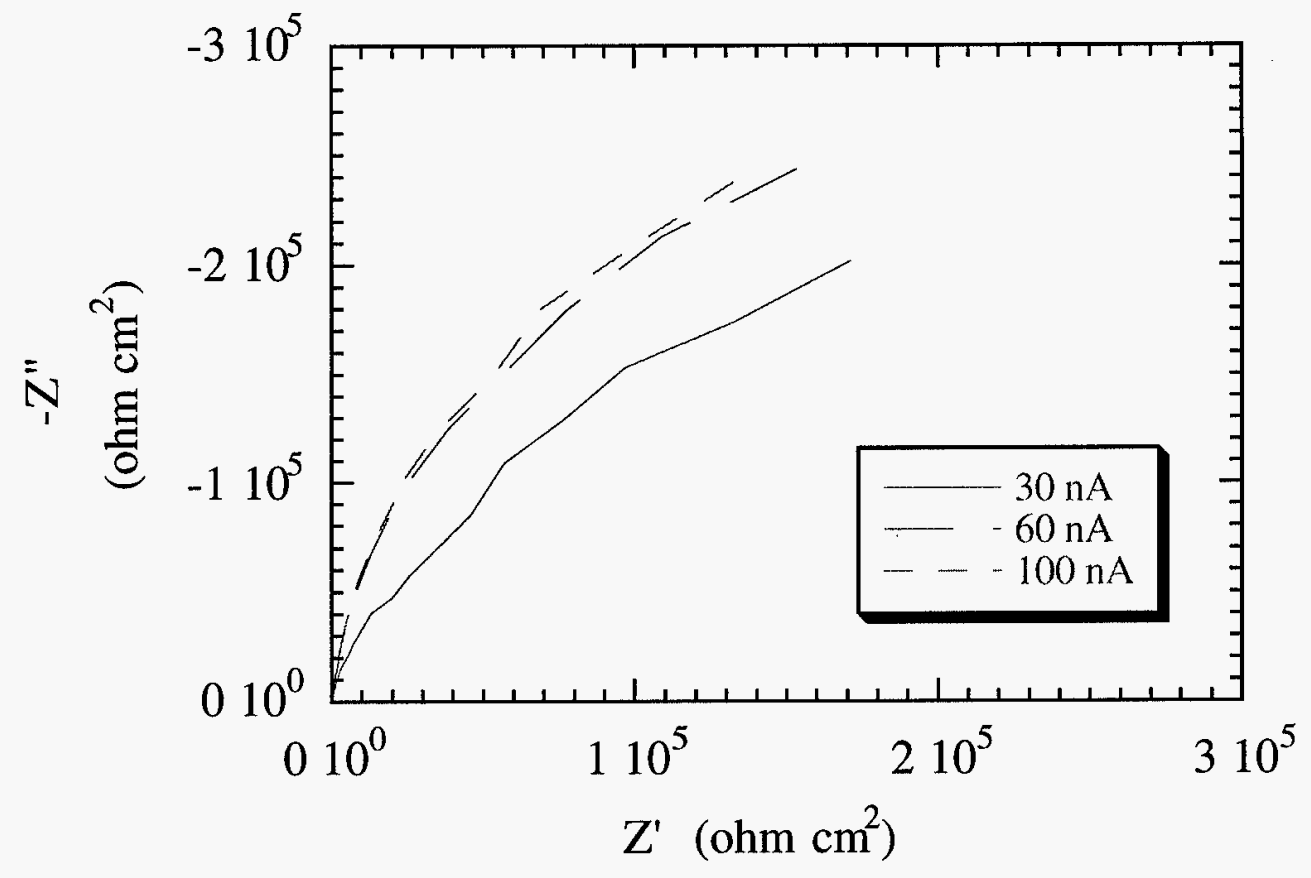

Figure 15 Nyquist plot for $\mathrm{Ta}$ in $\mathrm{H}_{2} \mathrm{SO}_{4}$, pH 1.6 at an applied potential of $+0.580 \mathrm{~V}$ SCE. Plot shows the effect of beam current on passive dissolution rate.

the corrosion current density associated with the out-of-beam sample appears to be similar to that of the sample at $100 \mathrm{nA}$ as observed for SS304. As was the case in the SS304 experiments, $i_{\text {pass }}$ for the in-beam was somewhat lower than $i_{\text {pass }}$ for the out-of-beam sample. Although this difference is small it was reproducible and, in conjunction with the EIS measurements discussed above, where the charge transfer resistance was found to increase with beam current, there is a convincing argument that passive dissolution of $\mathrm{Ta}$ is lowered by interactions with high energy proton irradiation. During the reverse scan direction in the in-beam polarization curve, a sharp step to lower current densities was observed when the proton beam was shut off as observed for SS304. At $0.300 \mathrm{~V} \mathrm{SCE}$ the beam was shut off and the current decreased from $6 \times 10^{-8} \mathrm{~A} / \mathrm{cm}^{2}$ to a current 


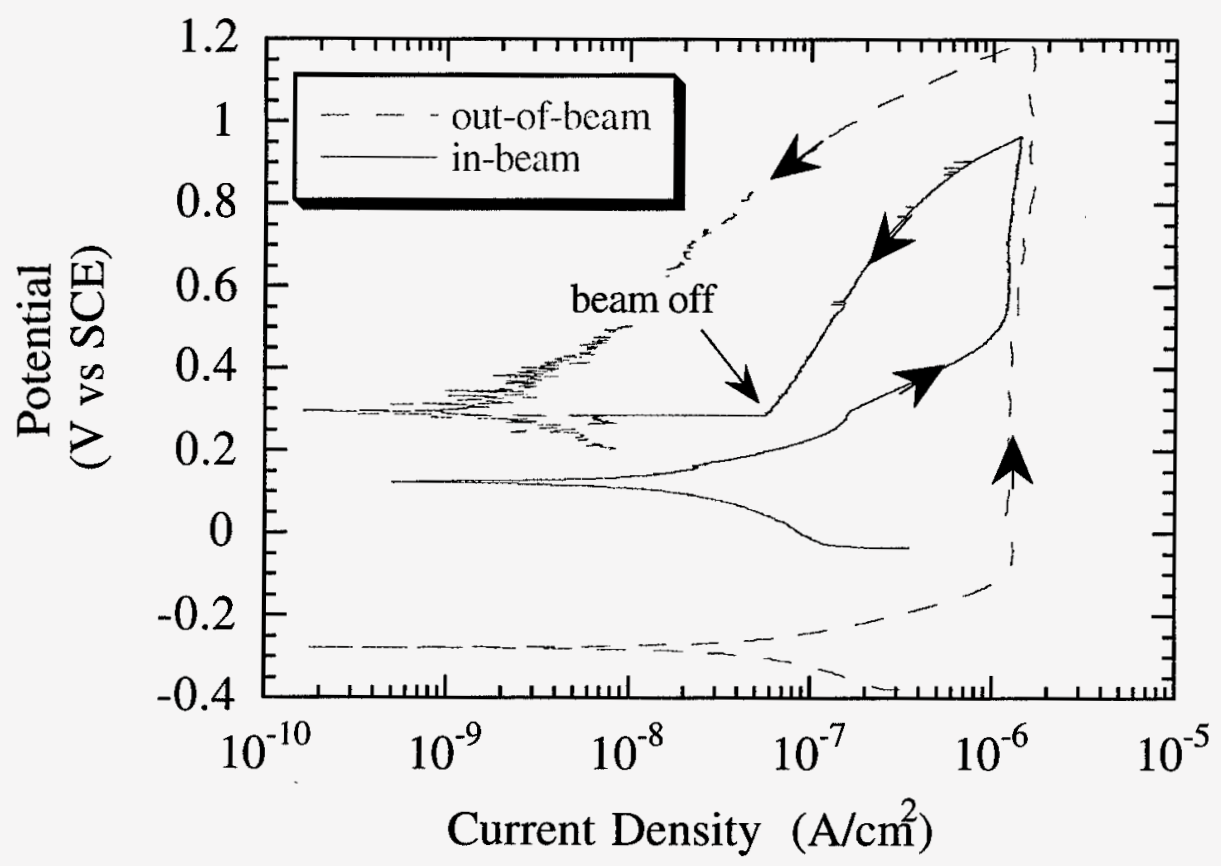

Figure 16 Potentiodynamic polarization curves for $\mathrm{Ta}$ in $\mathrm{H}_{2} \mathrm{SO}_{4} \mathrm{pH} 1.6$ for a sample during irradiation at a proton beam current of $100 \mathrm{nA}$ (in-beam) and a sample not exposed to irradiation (out-of-beam).

density of $7 \times 10^{-9} \mathrm{~A} / \mathrm{cm}^{2}$ at $0.749 \mathrm{~V}$ SCE. A decrease in current density by a factor of approximately 10 .

Potentiodynamic polarization curves for $\mathrm{Ta}$ in $0.1 \mathrm{M} \mathrm{NaCl}$ are presented in Figure 17 for samples during irradiation at a proton beam current of $100 \mathrm{nA}$ (in-beam) and not exposed to irradiation (out-of-beam). Once again, the in-beam anodic current densities in the forward portion of the curve were smaller than those measured for the out-of-beam sample while the anodic current densities measured during the reverse portion of the scan were higher. These results indicate that Ta is less susceptible to enhanced dissolution during proton irradiation as compared to $\mathrm{W}$ and SS304. 


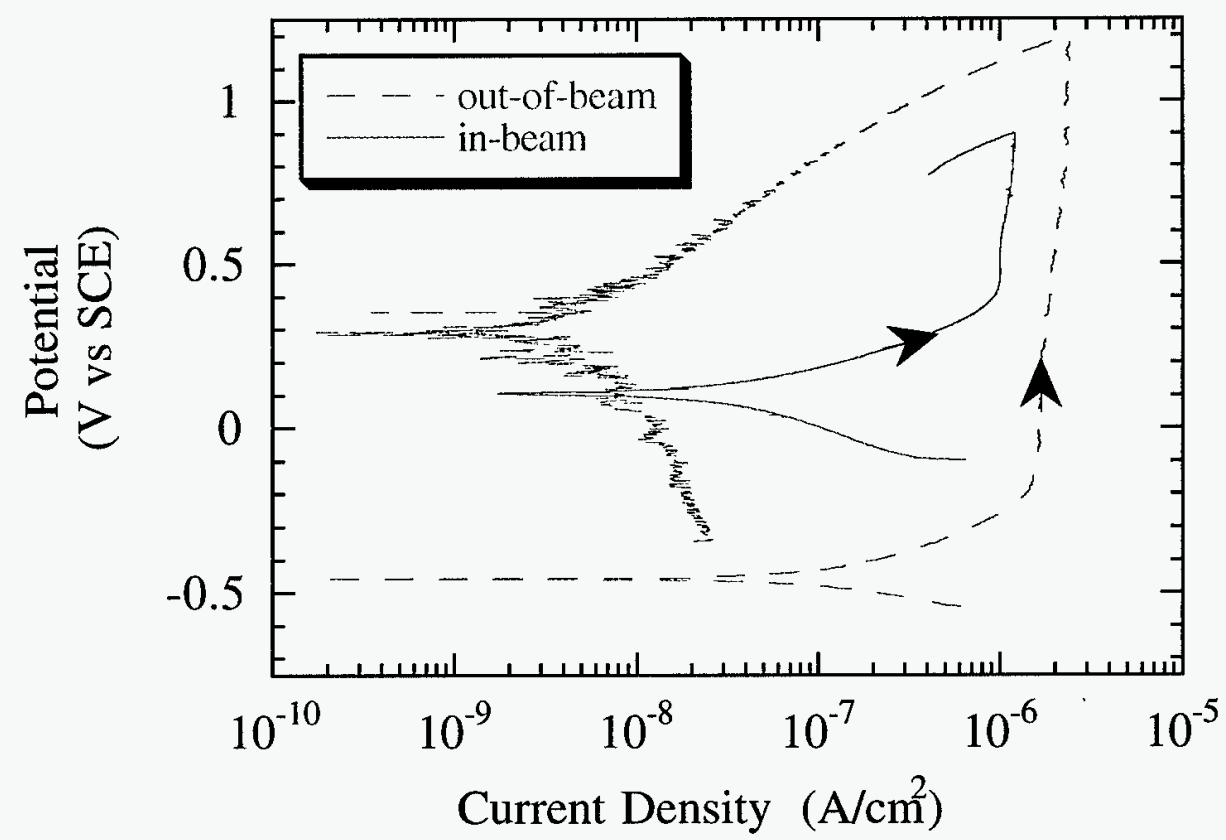

Figure 17 Potentiodynamic polarization curves for $\mathrm{Ta}$ in $0.1 \mathrm{M} \mathrm{NaCl}$ for a sample during irradiation at a proton beam current of $100 \mathrm{nA}$ (in-beam) and a sample not exposed to irradiation (out-of-beam).

Effects of Proton Irradiation on Gold Cyclic voltamograms (CV's) for gold (Au) in $\mathrm{H}_{2} \mathrm{SO}_{4} \mathrm{pH}$ 1.6 during irradiation at proton beam currents of 35, 60, and $100 \mathrm{nA}$ are presented in Figure 18. Not shown is the pre-irradiation $\mathrm{CV}$ which was similar to that measured during the $35 \mathrm{nA}$ experiments These curves were generated after cathodic polarization of the sample to reduce any oxide which had formed on the surface. As shown in Figure 18, upon anodic polarization of the sample from the OCP (approximately 0.60-0.69 V SCE) during irradiation at $35 \mathrm{nA}$, only small increases in the anodic current were observed up to an applied potential of approximately $0.990 \mathrm{~V}$ SCE. Further increases in the applied anodic potential (from 0.990-1.40 V SCE) resulted in large

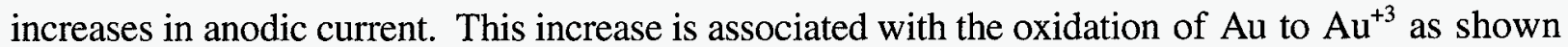
in the Pourbaix diagram for $\mathrm{Au}$ presented in Figure 19. This figure was generated for an $\mathrm{Au}^{+3}$ concentration of $10^{-6} \mathrm{M}$. Recall that Pourbaix diagrams only depict regions of thermodynamic stability and do not consider kinetic limitations. Upon reversing the scan direction at 1.4 V SCE, a 


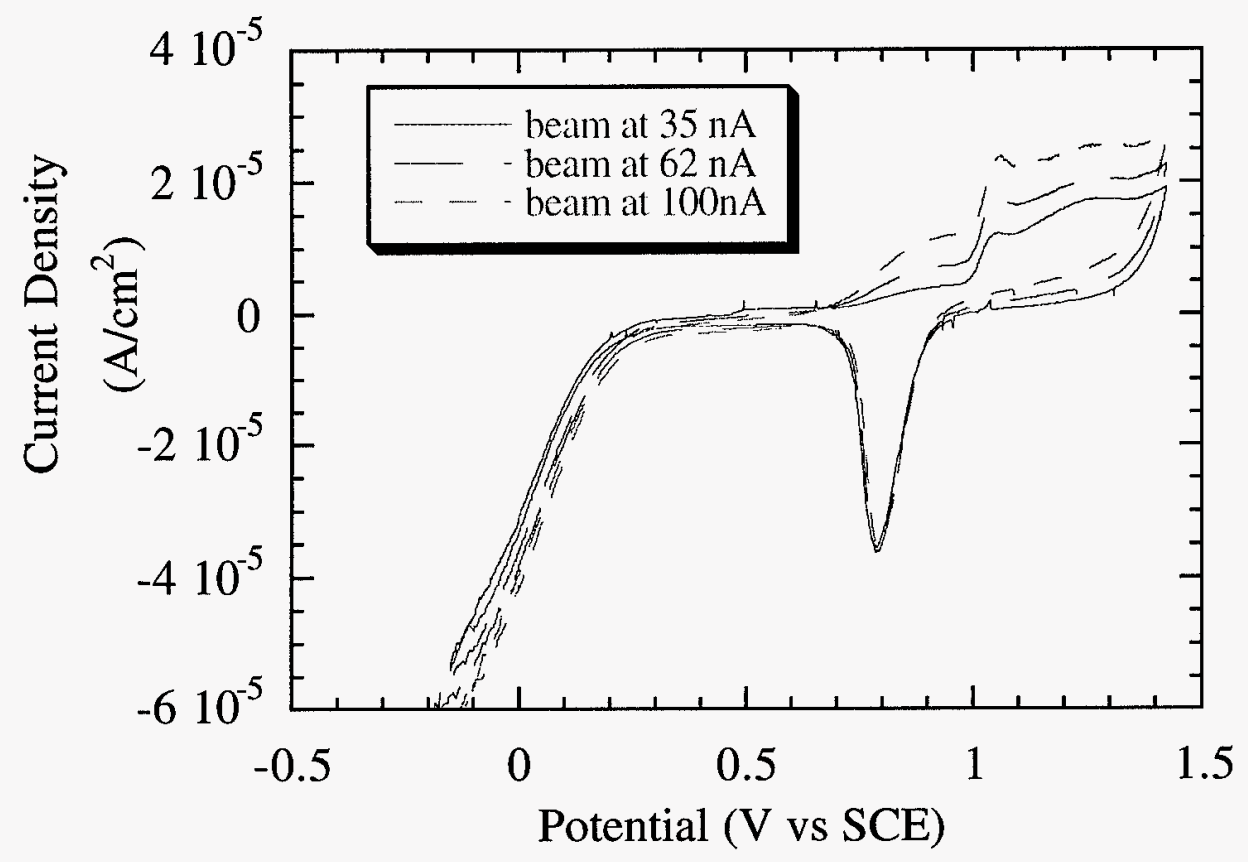

Figure 18 Cyclic voltamograms for gold in $\mathrm{H}_{2} \mathrm{SO}_{4} \mathrm{pH} 1.6$ during proton irradiation.

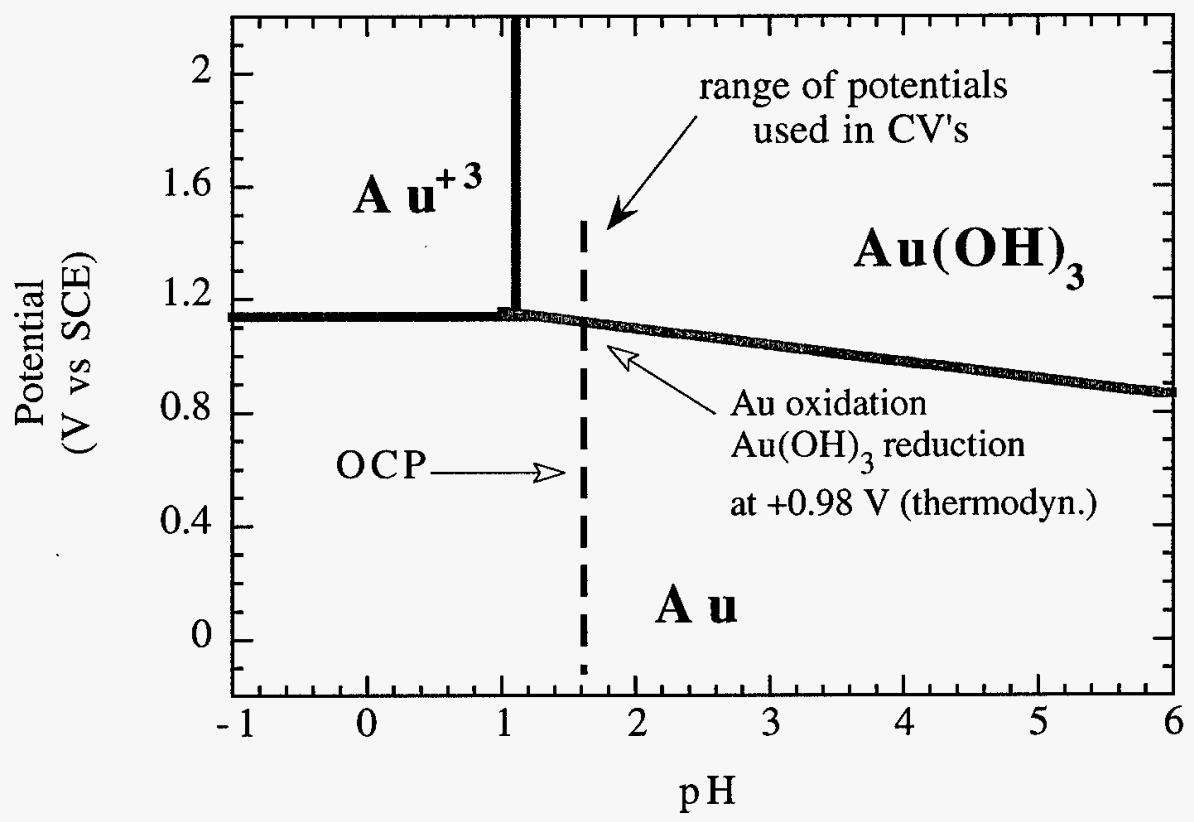

Figure 19 Pourbaix diagram for Au showing areas of thermodynamic stability. 
steady decrease in the anodic current density was measured (1.4 - 1.0 V SCE). This decrease is associated with a gold surface which is covered by an oxy-hydroxide that limits Au oxidation. At lower applied potentials (1.0 - $0.90 \mathrm{~V} \mathrm{SCE})$, a change from anodic to cathodic current was observed as was a peak in the cathodic current density between $1.0-0.60 \mathrm{~V}$ SCE. This peak is associated with $\mathrm{Au}^{+3}$ reduction to $\mathrm{Au}$. Once the oxy-hydroxide was completely reduced, the cathodic current density returned to lower values $(0.60-0.30 \mathrm{~V} \mathrm{SCE})$. Further discussion of these CV's will be limited to the potential regions of Au oxidation and reduction ( $0.30-1.4 \mathrm{~V} \mathrm{SCE})$.

Figure 20 presents a detailed representation of the Au oxidation - reduction region of the $\mathrm{CV}$ for the sample during irradiation at a proton beam current of $100 \mathrm{nA}$. As can be seen in this figure the Au oxidation peak occurred at a potential of $1.06 \mathrm{~V} \mathrm{SCE}$ while the reduction peak occurred at a potential of $-0.790 \mathrm{~V} \mathrm{SCE}$. Both the oxidation and reduction peak position were found to be independent of presence of irradiation or proton beam current (Figure 19). Proton current was found to change the total anodic current. At applied potentials more positive than 0.70 V SCE, the total anodic current density was found to increase with increasing proton beam current. As no change in the area under the reduction peak was observed with increasing proton beam current, it does not appear that the increased anodic current density is associated with the formation of $\mathrm{Au}(\mathrm{OH})_{3}$. If the amount of $\mathrm{Au}$ oxidized to $\mathrm{Au}(\mathrm{OH})_{3}$ increased with increasing beam current, this "extra" hydroxide would also be reduced in the reverse scan. As the area under the reduction peak is proportional to charge passed (or quantity of a single species being reduced), an increase in area would also be measured. While the increased anodic current observed during proton irradiation may result from an increase in soluble $\mathrm{Au}^{+3}$, it may also result from an oxidation reaction unrelated to $\mathrm{Au}$, such as that from a water radiolysis product. Currently, we are pursuing additional laboratory experiments to either verify or rule out the presence of $\mathrm{H}_{2} \mathrm{O}_{2}$ as a possible cause for this phenomenon. 


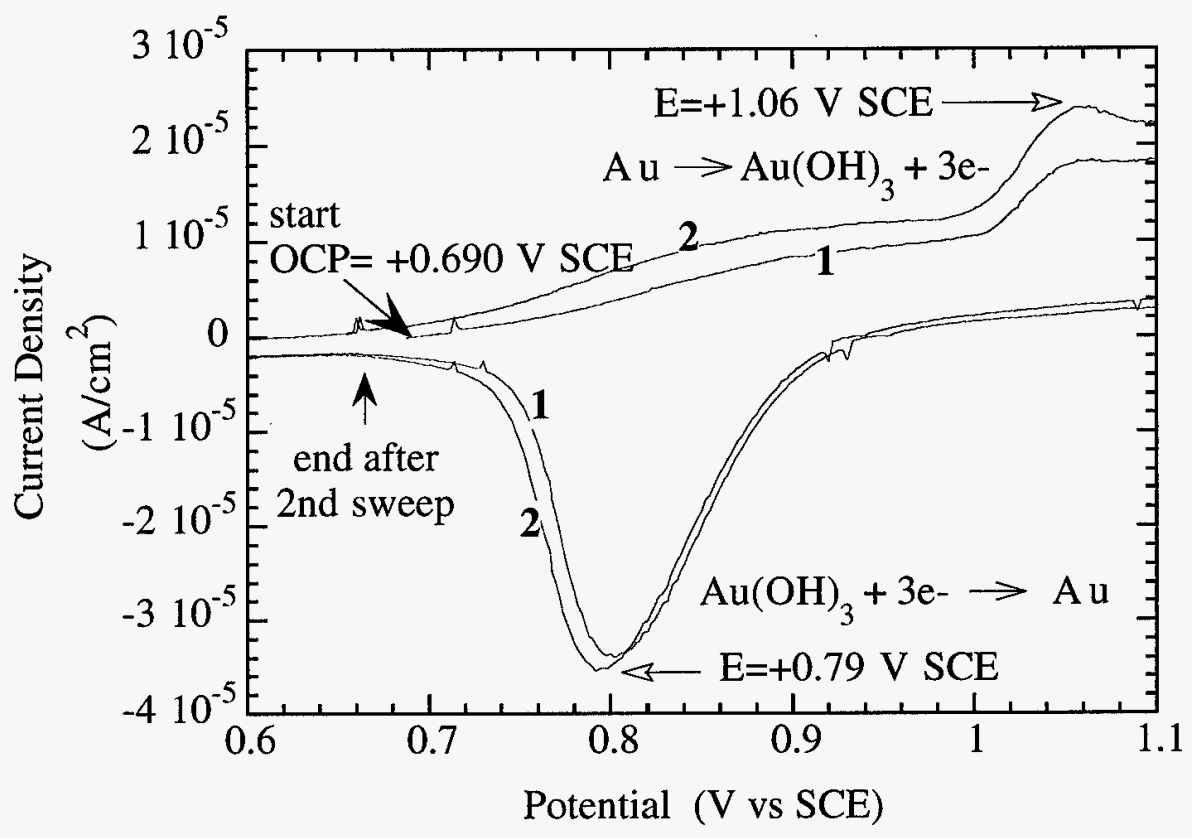

Figure 20 Detailed representation of the Au oxidation / reduction region of the $\mathrm{CV}$ for the sample during irradiation at a proton beam current of $100 \mathrm{nA}$

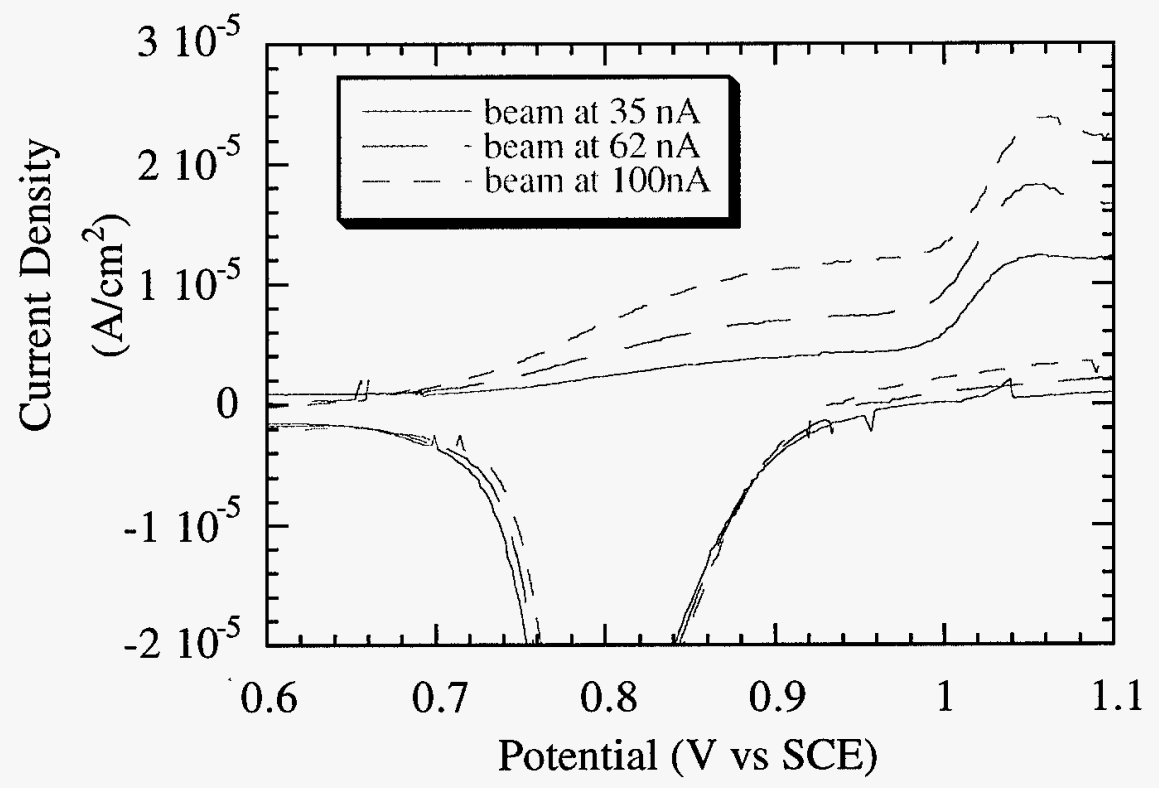

Figure 21 Detailed representation of the Au oxidation / reduction region of the CV in Figure 19 for all beam currents examined. 
Thermal Hydraulic Considerations To rule out an increase in sample temperature (which may result from proton beam energy deposition) as a possible mechanism for the observed electrochemical effects during irradiation energy deposition and thermal hydraulic calculations for the rod-shaped tungsten target were performed. Calculations were limited to this specimen as its density and mass make it the most susceptible to energy deposition and a resulting increase in surface temperature. The distribution of beam energy across the sample is Gaussian. Assuming a beam width of $4 \mathrm{~mm}(2 \sigma=0.8 \mathrm{~cm})$ the peak power density at a beam current of $1 \mathrm{nA}$ was calculated to be $3.36 \times 10^{4} \mathrm{~W} / \mathrm{m}^{3}$. This assumption is conservative, as the beam spot was likely closer to $2 \mathrm{~cm}$ in diameter as opposed to $1 \mathrm{~cm}$. For the beam currents examined here the peak power densities were therefore: $1.68 \times 10^{6} \mathrm{~W} / \mathrm{m}^{3}, 4.74 \times 10^{6} \mathrm{~W} / \mathrm{m}^{3}, 1.18 \times 10^{7} \mathrm{~W} / \mathrm{m}^{3}$ and $1.63 \times 10^{7} \mathrm{~W} / \mathrm{m}^{3}$.

The solution velocity past the half round tungsten rod of diameter $0.318 \mathrm{~cm}$ for a cell $\mathrm{ID}$ of $1.9 \mathrm{~cm} \mathrm{x} 1.9 \mathrm{~cm}$ and a solution flow rate of $17.07 \mathrm{~cm}^{3} / \mathrm{s}(1.024 \mathrm{~L} / \mathrm{min})$ was $5.16 \mathrm{~cm} / \mathrm{s}$. For the remainder of the cell the velocity was approximately $4.73 \mathrm{~cm} / \mathrm{s}$. The Reynolds number for the minimum area around the $\mathrm{W}$ sample was 183 while that for the remainder of the cell was 168 . The heat transfer coefficients calculated for the given maximum and minimum velocities using a cylinder model[20] are 2667 and $2553 \mathrm{~W} / \mathrm{m}^{2}$-C respectively.

The estimated surface temperatures for the tungsten target were calculated using 2 approximations. The first assumes a round rod of the diameter used in these experiments. The maximum surface temperatures (for a beam current of $484 \mathrm{nA}$ ) are $4.8^{\circ}$ and $5.1^{\circ} \mathrm{C}$ above the water temperature $\left(30.8^{\circ}\right.$ and $\left.31.1^{\circ} \mathrm{C}\right)$. In this model the sample temperature distribution was determined to be essentially uniform as the $\Delta \mathrm{T}$ from the center of the sample to the sample surface in this model was only $0.03^{\circ} \mathrm{C}$. The second model used the actual half round rod geometry of the actual tungsten target and the assumption of uniform surface heat flux. For this model the maximum surface temperatures (for beam currents of $484 \mathrm{nA}$ ) were only 3.0 and $3.1^{\circ} \mathrm{C}$ above the water temperature $\left(29.0^{\circ}\right.$ and $\left.29.1^{\circ} \mathrm{C}\right)$. Because the reaction rate scales with $\mathrm{RT} / \mathrm{nF}$ where $\mathrm{T}$ is the 
temperature in degrees Kelvin, from these results we can conclude that surface temperature effects are not a factor which must be considered in the in-beam experiments.

\section{Summary}

Electrochemical experiments for W, Ta, SS304, and $\mathrm{Au}$ were conducted in $\mathrm{H}_{2} \mathrm{SO}_{4} \mathrm{pH} 1.6$ and $0.1 \mathrm{M} \mathrm{NaCl} \mathrm{pH} 5.2$ as a function of proton fluence. In these experiments, the open circuit potential for all materials increased with increasing proton fluence. In addition the corrosion current density for W and SS304 were found to increase with increasing proton fluence. The passive dissolution rate for SS304 and Ta decreased with increasing proton fluence while that for $\mathrm{W}$ increased. In addition, an increase in pitting potential for SS304 was observed in $0.1 \mathrm{M} \mathrm{NaCl}$ during irradiation at a proton beam current of $100 \mathrm{nA}$. More positive pitting potentials are generally associated with a decrease in susceptibility to localized corrosion.

Cyclic voltamograms for $\mathrm{Au}$ in $\mathrm{H}_{2} \mathrm{SO}_{4}, \mathrm{pH} 1.6$, found that both the oxidation and reduction peak positions (associated with $\mathrm{Au}(\mathrm{OH})_{3}$ formation and reduction) were independent of the presence of irradiation or proton beam current. Proton current was found to change the total anodic current. As no change in the area under the reduction peak was observed with increasing proton beam current, it does not appear that the increased anodic current density is associated with the formation of $\mathrm{Au}(\mathrm{OH})_{3}$. If the amount of $\mathrm{Au}$ oxidized to $\mathrm{Au}(\mathrm{OH})_{3}$ increased with increasing beam current, this "extra" hydroxide would also be reduced in the reverse scan. As the area under the reduction peak is proportional to charge passed (or quantity of a single species being reduced), an increase in area also would be measured. While the increased anodic current observed during proton irradiation may result from an increase in soluble $\mathrm{Au}+3$, it may also results from an oxidation reaction unrelated to $\mathrm{Au}$, such as that from a water radiolysis product. Currently, we are pursuing additional laboratory experiments to either verify or rule out the presence of $\mathrm{H}_{2} \mathrm{O}_{2}$ as a possible cause for this phenomenon. 


\section{References}

$1 \quad$ M.Simnad and R. Smoluchowski, Physics Review, vol.99 pp. 1891-2, 1955.

$2 \quad$ M.Simnad and R. Smoluchowski, Physics Review, vol.98, pp.1961-2, 1955.

3 F.E. Hoyer, " Radiolytic Corrosion in Cooling Water Circuits of High Energy Particle Accelerators and its Inhibition", in Proceedings, Fourth International Congress on Metallic Corrosion, N.E. Hamner ed., NACE, Houston, pp. 164-76, 1972.

4 J.L. Magee, A. Chatterjee, in Kinetics of Nonhomogeneous Processes, G.R. Freeman ed., John Wiley \& Sons, New York, pp171-214, 1987.

$5 \quad$ H. Christensen, Nuclear Technology, vol. 109, pp. 373-82, 1994.

6 T.K. Yeh, D.D. Macdonald, A.T. Motta, Nuclear Science and Engineering, vol. 121, pp 468-82, 1995.

7 W.G. Burns, P.B. Moore, Radiation Effects, vol. 30, pp. 233-42, 1976.

8 D.D. Macdonald, H. Song, K. Makela, K. Yoshida, Corrosion, vol. 49, no. 1, pp. 8-16, 1993.

$9 \quad$ J.R. Macdonald, Impedance Spectroscopy, Wiley Publishing, New York, 1987.

10 I. Epelboin, C. Gabrielli, M. Keddam, H. Takenouti, "Alternating-Current Impedance Measurements and Corrosion Rate Determination", in Electrochemical Corrosion Testing. ASTM STP 727, F. Mansfeld \& U. Bertocci eds., ASTM, Ohio, pg. 150-66, 1981

11 D.D. MacDonald, M.C.H. Mckubre, "Electrochemical Impedance Techniques in Corrosion Science" in Electrochemical Corrosion Testing. ASTM STP 727, F. Mansfeld \& U. Bertocci eds., ASTM, Ohio, pg. 110-59, 1981

12 M.J. Danielson, Corrosion, vol. 51, no. 6, pp. 450-455, 1995.

13 R.D. Armstrong, K. Edmoson, R.E. Firman, Journal of Electroanalytical Chemistry, vol. 40, pp. 19-25, 1972.

14 D.C. Grahame, The Journal of the Electrochemical Society, vol. 99, no. 12, pp370C385C, 1952.

15 J.E.B. Randles, Discussion of the Faraday Society, vol. 1, pp11-19, 1947.

16 H. Gerisher, Zeitschrift fur Physike Chemie, vol. 201, pg 55, 1952.

17 R.D. Armstrong, M.F. Bell, A.A. Metcalfe, Electrochemistry, Specialist Periodical Reports, vol. 6, pp98-127, 1978.

18 E. Gileadi, Electrode Kinetics for Chemists, Chemical Engineers \& Material Scientists, VCH Publishers, New York, 1993. 
19 E. Sikora, C. Breslin, J. Sikora, D.D. MacDonald, "Semiconducting Properties of Passive Films on Types 304 and 316 Stainless Steel Formed Under UV-Irradiation", in Critical Factors in Localized Corrosion, P.M. Natishan, R.G. Kelly, G.S. Frankel, R.C.

Newman, proceedings vol 95-15, ECS, Pennington, NJ, pp344-354, 1995

20 Zhukasukas, A., "Heat Transfer from Tubes in Cross Flow", in Advances in Heat Tranfer, Vol. 8, ,J.P. Hartnettand T. F. Irvine, Jr., Eds., Academic Press, New York, 1972. 


\section{M98004316}

|[I.|.|.

Report Number (14) LA-UK--97-50/I

Publ. Date (11)

199712

Sponsor Code (18)

UC Category (19)

(18) DOE /DP; DOE/DT, XF uC-704;4C-700, DOE/ER 